\title{
Preservation of Cone Photoreceptors after a Rapid yet Transient Degeneration and Remodeling in Cone-Only $\mathrm{Nrl}^{-1-}$ Mouse Retina
}

\author{
Jerome E. Roger, ${ }^{1}$ Keerthi Ranganath, ${ }^{1}$ Lian Zhao, ${ }^{2}$ Radu I. Cojocaru, ${ }^{1}$ Matthew Brooks, ${ }^{1}$ Norimoto Gotoh, ${ }^{1}$ \\ Shobi Veleri, ${ }^{1}$ Avinash Hiriyanna, ${ }^{1}$ Rivka A. Rachel, ${ }^{1}$ Maria Mercedes Campos,,${ }^{3}$ Robert N. Fariss, ${ }^{3}$ Wai T. Wong, ${ }^{2}$ \\ and Anand Swaroop ${ }^{1}$ \\ ${ }^{1}$ Neurobiology-Neurodegeneration and Repair Laboratory, ${ }^{2}$ Unit on Neuron-Glia Interactions, ${ }^{3}$ Biological Imaging Core, National Eye Institute, National \\ Institutes of Health, Bethesda, Maryland 20892
}

\begin{abstract}
Cone photoreceptors are the primary initiator of visual transduction in the human retina. Dysfunction or death of rod photoreceptors precedes cone loss in many retinal and macular degenerative diseases, suggesting a rod-dependent trophic support for cone survival. Rod differentiation and homeostasis are dependent on the basic motif leucine zipper transcription factor neural retina leucine zipper (NRL). The loss of $\mathrm{Nrl}\left(\mathrm{Nrl}^{-1-}\right)$ in mice results in a retina with predominantly S-opsin-containing cones that exhibit molecular and functional characteristics of wild-type cones. Here, we report that $\mathrm{Nrl}^{-1-}$ retina undergoes a rapid but transient period of degeneration in early adulthood, with cone apoptosis, retinal detachment, alterations in retinal vessel structure, and activation and translocation of retinal microglia. However, cone degeneration stabilizes by 4 months of age, resulting in a thinner but intact outer nuclear layer with residual cones expressing S- and M-opsins and a preserved photopic electroretinogram. At this stage, microglia translocate back to the inner retina and reacquire a quiescent morphology. Gene profiling analysis during the period of transient degeneration reveals misregulation of genes related to stress response and inflammation, implying their involvement in cone death. The $\mathrm{Nrl}^{-1-}$ mouse illustrates the long-term viability of cones in the absence of rods and retinal pigment epithelium defects in a rodless retina. We propose that $\mathrm{Nrl}^{-1-}$ retina may serve as a model for elucidating mechanisms of cone homeostasis and degeneration that would be relevant to understanding diseases of the cone-dominant human macula.
\end{abstract}

\section{Introduction}

Retinal neurodegeneration is a common feature of many blinding diseases in the developed world. Among inherited retinal diseases (http://www.sph.uth.tmc.edu/retnet/), a majority is associated with the dysfunction or death of photoreceptors (Jackson et al., 2002; Bramall et al., 2010; Swaroop et al., 2010; Wright et al., 2010). The rod photoreceptors allow vision under dim light and are capable of catching a single photon, while cone photoreceptors mediate day light vision, color perception, and visual acuity (Luo et al., 2008; Mustafi et al., 2009). Any impediment in the photoreceptor metabolism or function, caused by genetic defects or microenvironment, can lead to cell death.

While rod photoreceptors die first in retinitis pigmentosa (RP) and age-related macular degeneration (AMD), the death of

Received July 8, 2011; revised Sept. 13, 2011; accepted Nov. 4, 2011.

Author contributions: J.E.R., K.R., W.T.W., and A.S. designed research; J.E.R., K.R., L.Z., R.I.C., M.B., N.G., S.V., A.H., R.A.R., M.M.C., and R.N.F. performed research; J.E.R., K.R., L.Z., R.I.C., N.G., R.A.R., R.N.F., W.T.W., and A.S. analyzed data; J.E.R. and A.S. wrote the paper.

This work was supported by the intramural program of the National Eye Institute. We thank Harsha Rajasimha for help with RNAseq data and Chun Y. Gao for technical assistance.

Correspondence should be addressed to Anand Swaroop, Neurobiology-Neurodegeneration and Repair Laboratory, National Eye Institute, National Institutes of Health, 6 Center Drive, Bethesda, MD 20892. E-mail: swaroopa@nei.nih.gov.

DOI:10.1523/JNEUROSCI.3591-11.2012

Copyright $\odot 2012$ the authors $\quad 0270-6474 / 12 / 320528-14 \$ 15.00 / 0$ cones follows (Jackson et al., 2002; Punzo et al., 2009; Wright et al., 2010), suggesting a non-cell-autonomous mechanism of cone survival and/or death. The secondary cone death could result from the absence of a neurotrophic factor or a rod-derived survival factor (Faktorovich et al., 1990; Léveillard et al., 2004) or nutritional imbalance including compromised glucose uptake (Punzo et al., 2009). The study of cone photoreceptors has been difficult because of their relatively low proportion in the retina in mice and humans (Curcio et al., 1990; Mustafi et al., 2009) and/or other significant limitations (including the breeding of study models, antibody availability, and genetics) (Kryger et al., 1998; Hendrickson and Hicks, 2002; Bobu et al., 2006).

The neural retina leucine zipper $(\mathrm{Nrl})$ gene encodes a basic motif leucine zipper transcription factor that is necessary for rod cell fate determination during retinal development (Swaroop et al., 2010). The loss of $\mathrm{Nrl}\left(\mathrm{Nrl}^{-1-}\right)$ in mice leads to a cone-only retina with the complete absence of rods and photoreceptors with S-cone like characteristics but shorter outer segments (OSs) (Mears et al., 2001). The photoreceptors in $\mathrm{Nrl}^{-1-}$ mice express cone-specific genes (Yoshida et al., 2004; Akimoto et al., 2006), have morphological and physiological features of cones (Daniele et al., 2005; Nikonov et al., 2005), yet seem to establish synaptic connections with rod bipolar cells (Strettoi et al., 2004). The analyses of $R p e 65^{-1-}$ and $\mathrm{Grk1} 1^{-1-}$ mice on $\mathrm{Nrl}{ }^{-1-}$ background have revealed novel insights into cone visual cycle (Zhu et al., 2003; 
A

$N r^{+/+}$

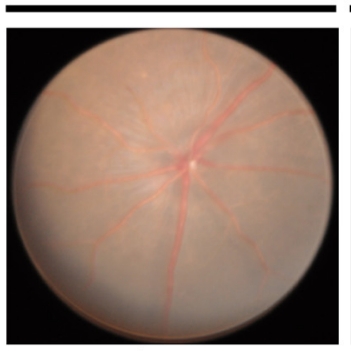

1 mon

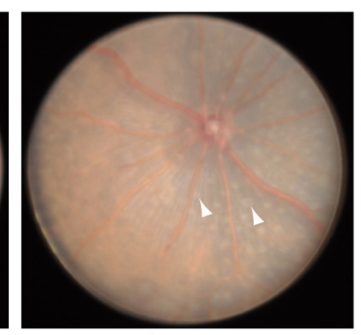

1 mon

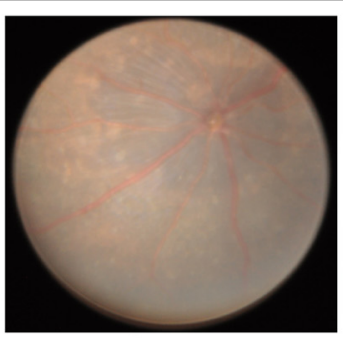

2 mon

B
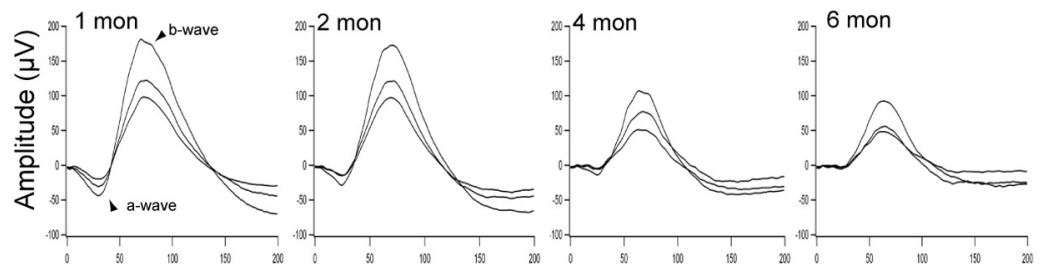

Time (ms)

D
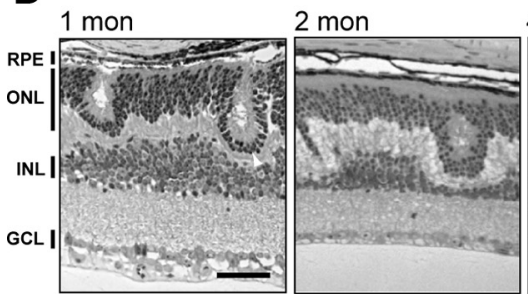

4 mon

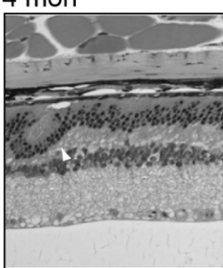

E
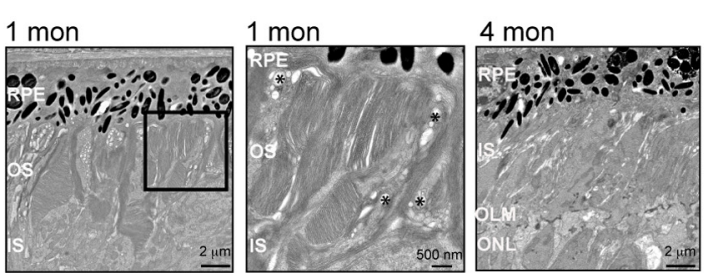

$10 \mathrm{mon}$
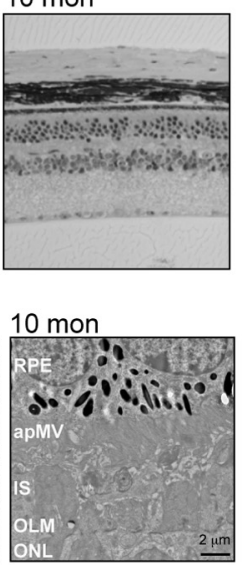

Nrl $\%$

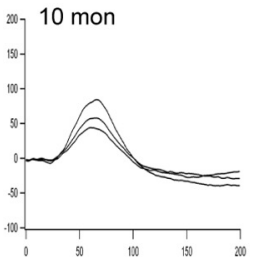

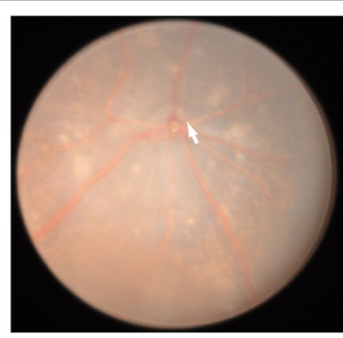

6 mon

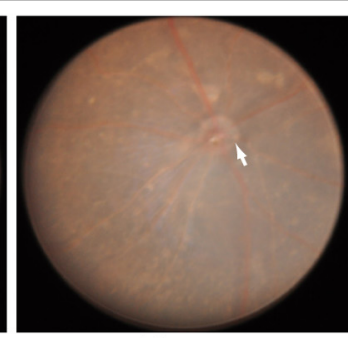

10 mon

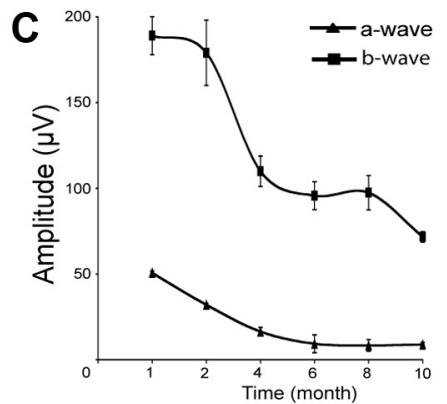

$\mathbf{F}$

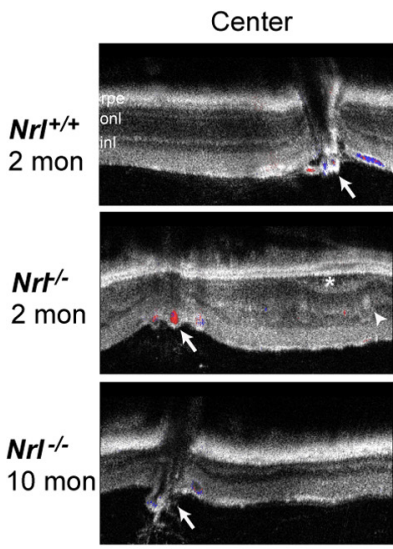

Periphery

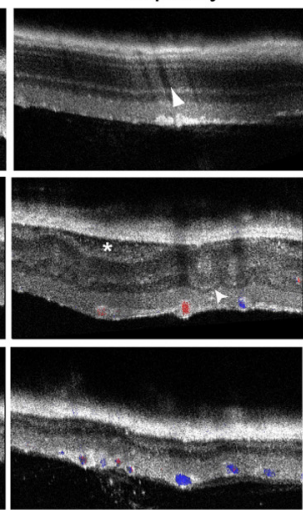

Figure 1. Cone degeneration in $\mathrm{Nrl}^{-1-}$ mice. A, Fundus image of 1-month-old WT and 1-, 2-, 6-, and 10-month-old $\mathrm{Nrl}^{-1-}$ mice. The white dots corresponding to pseudorosettes were observed in $\mathrm{Nrl}^{-I-}$ mice at 1 and 2 months of age (white arrowheads). Attenuated blood vessels were observed in 10-month-old $\mathrm{Nrl}^{-/-}$mice and optic atrophy increased at 6 months (white arrows). $\boldsymbol{B}$, Light-adapted $\mathrm{Nrl}^{-1-}$ mice ERG recording showed a decrease between 1 and 4 months of age of a- and b-waves. $\boldsymbol{C}$, Average of the maximum amplitude for a- and b-wave in $\mathrm{Nrl}^{-1-}$ mice at $1,2,4,6$, and 10 months of age. The maximum decrease is observed between 2 and 4 months. Error bars show \pm SEM from four independent mice. $\boldsymbol{D}$, Methacrylate sections followed by H\&E staining on 1-, 2-, 4-, and 10-month-old $\mathrm{Nrl}^{-1-}$ mouse retina showed a loss of nuclei in the onl between 1 and 4 months. Rpe, Retinal pigment epithelium; onl, outer nuclear layer; inl, inner nuclear layer; gcl, ganglion cell layer. Scale bar, $20 \mu \mathrm{m}$. E, Transmission EM images of $\mathrm{Nrl}^{-1-}$ mouse retina in the dorsal-ventral midline plane, taken through the central retina, at 1, 4, and $10 \mathrm{months}$ of age. Rudimentary 0 Ss are evident at 1 month but not at 4 and 10 months. Abnormal accumulation of IS material is detected in the ONL at 4 and 10 months; the ONL in WT mice contains primarily nuclei (data not shown). The stacked membranous structures at the RPE-subretinal interface correspond to apical microvilli of the RPE, identified by their position, spacing, and length. Scale bar, $2 \mu \mathrm{m}$. OSs in 1-month-old retina are shown at higher magnification. Note that, while regular stacks of discs begin to form, they do not elongate (as in WT mice). Some areas of abnormal membrane vesicle formation are present (asterisks). Scale bar, $500 \mathrm{~nm}$. apMV, apical microvilli of the RPE; OLM, outer limiting membrane. $\boldsymbol{F}$, OCT images of 2-month-old WT retina and 2-and 10-month-old $\mathrm{NrI}^{-1-}$ retina. (enter and periphery areas of the retina were imaged. In old animals, ONL is thinner, and large arteries were observed by OCT Doppler (red and blue color indicated by white arrows). Areas of retinal detachment (asterisk) and pseudorosettes (arrowheads) were observed only in the central part and periphery of the 2-month-old $\mathrm{Nrl}^{-1-}$ retina. $^{-}$

Wenzel et al., 2007; Feathers et al., 2008; Kunchithapautham et al., 2009).

Given the relative importance of cones in human vision and the utility of $\mathrm{Nrl}^{-1-}$ mice for delineating cone biology, we undertook a comprehensive evaluation of cone-only $\mathrm{Nrl}^{-1-}$ retina. Here, we report our unusual findings of rapid yet transient cone cell death between 1 and 4 months of age, with a subsequent stabilization of the remaining cone number and function. This observation is different from progressive photoreceptor degeneration in rodent models of RP, yet highly significant since macular cones are preserved for longer periods in many RP patients. Our studies also show that cones can survive and function for extended periods even in the absence of rod photoreceptors.

\section{Materials and Methods}

Animal and tissue collection. $\mathrm{Nrl}^{-1-}$ mice (Mears et al., 2001) were established on C57BL/6J background. Mice of either sex were used in the study and killed by $\mathrm{CO}_{2}$ inhalation. Mouse eyeballs were fixed in $4 \%$ paraformaldehyde for $1 \mathrm{~h}$ on ice, incubated in an increasing concentration of PBS/sucrose $(10,20,30 \%)$, and embedded in Tissue-Tek CRYO-OCT compound (Thermo Fisher Scientific) for cryosection. For plastic sections, eyeballs were first fixed in $4 \%$ glutaraldehyde for $30 \mathrm{~min}$ before 
A
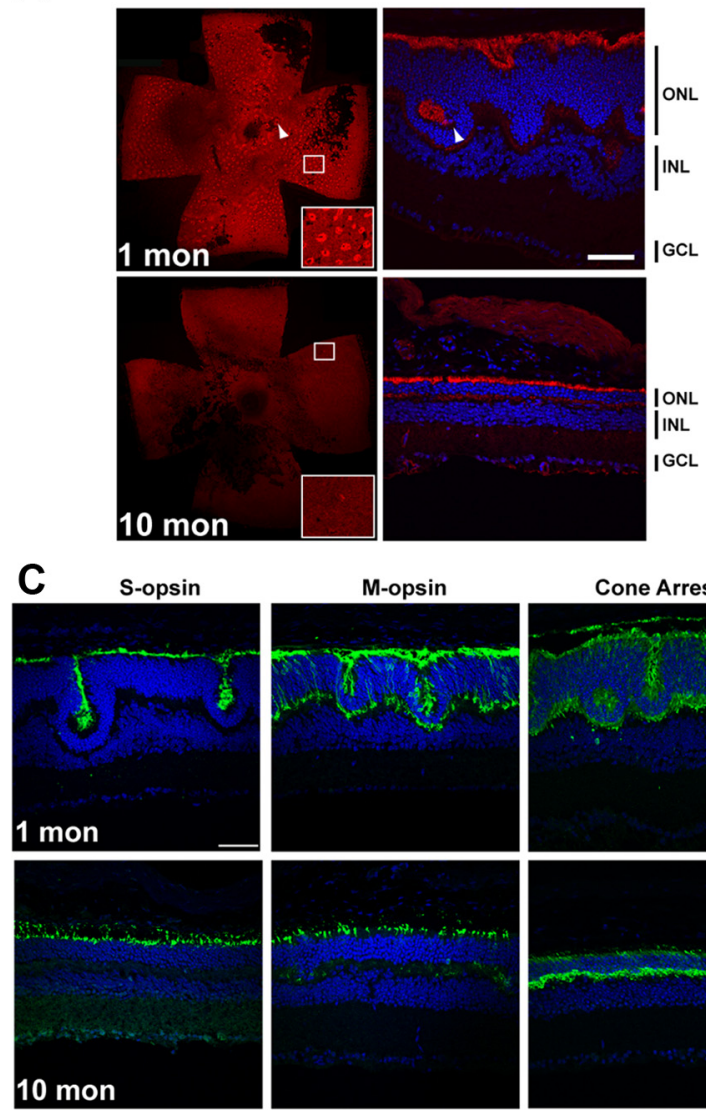

Cone Arrestin

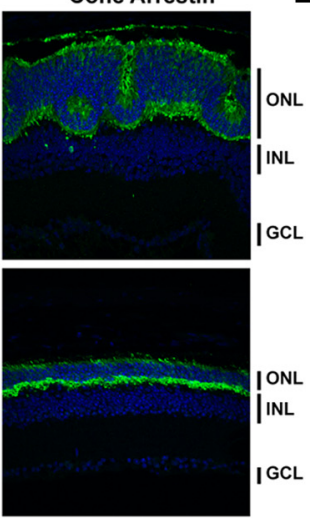

B

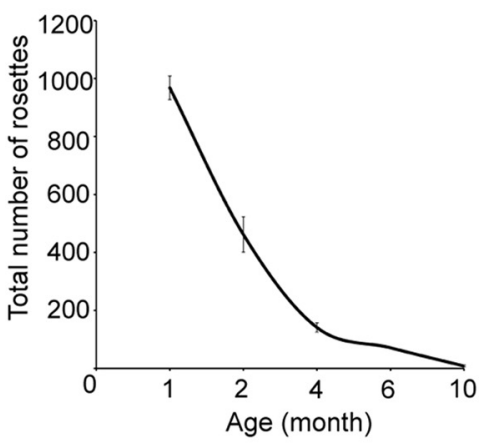

D

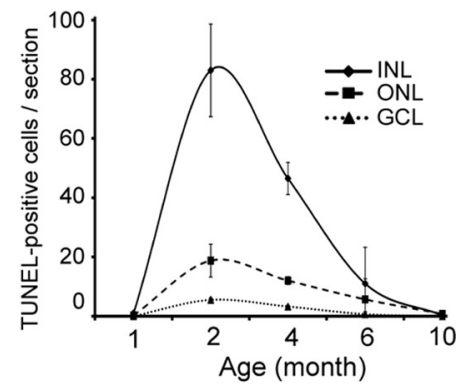

Figure 2. Transitory cell death between 1 and 4 months in $\mathrm{Nrl}^{-1-}$ retina. A, Identification of pseudorosettes with PNA on flat-mount retina and cryosections on 1- and 10-month-old $\mathrm{Nrl}^{-1-}$ mice. $\boldsymbol{B}$, Average of the number of pseudorosettes in $\mathrm{Nrl}^{-1-}$ mice counted after labeling with PNA on flat-mount retina at 1, 2, 4,6, and 10 months of ages. The maximum decrease is observed between 1 and 4 months. Error bars show \pm SEM from four independent mice. C, S-opsin, M-opsin, and cone arrestin immunostaining (green) in 1- and 10-month-old NrI ${ }^{-1-}$ retina show maintenance of expression in old mice. D, By TUNEL assay, quantification of apoptotic cells per section in the outer nuclear layer (dashed line), inner nuclear layer (solid line), and ganglion cell layers (dotted line), separately in 1-, 2-, 4-, 6-, and 10-month-old $\mathrm{Nrl}^{-/-}$mice. Error bars show \pm SEM from four independent mice. The data show cell death in all retinal layers between 2 and 4 months. The cell death was more pronounced in the inner nuclear layer compared with outer nuclear layer. A, C, Nuclei were visualized by DAPI staining. Scale bar, $20 \mu \mathrm{m}$.

overnight fixation in $4 \%$ paraformaldehyde. After embedding in methacrylate, $5-\mu$ m-thick sections were cut and stained with hematoxylin and eosin. For RNA extraction, the retinas were excised rapidly, frozen on dry ice, and stored at $-80^{\circ} \mathrm{C}$. Experimental procedures involving animals were performed according to animal protocols approved by the Animal Care and Use Committee at the National Eye Institute. Mice of either sex were used for experimental procedures.

Antibodies and dyes. The following primary antibodies were used: anti-cone arrestin, anti-Sox9, and anti-GFAP polyclonal antibodies (Millipore Bioscience Research Reagents); anti-Brn3a monoclonal antibody (Santa Cruz Biotechnology); acrolein polyclonal antibody (Abcam); peanut agglutinin conjugated to Alexa Fluor 568 (Invitrogen); anti-Neurofilament-L polyclonal antibody (Millipore); AKFluor-fluorescein (Akorn), Iba-1 (1:800; Wako Chemicals), Alexa Fluor 633-conjugated phalloidin (1:100; Invitrogen), RPE65 polyclonal antibody (T. M. Redmond, National Eye Institute, Bethesda, MD); anti-S-opsin and anti-M-opsin polyclonal antibodies (C. M. Craft, University of Pennsylvania, Philadelphia, PA). Secondary antibodies included goat anti-rabbit and anti-mouse antibodies conjugated with Alexa Fluor 488 and 568 (Invitrogen).

Immunohistochemistry and terminal deoxynucleotidyl transferasemediated biotinylated UTP nick end labeling assay. Cryosections were probed with specific antibodies, as previously described (Roger et al., 2006), and visualized using an Olympus FluoView FV1000 confocal laser-scanning unit and Olympus BX61WI upright microscope (Olympus America). Apoptosis was detected by terminal deoxynucleotidyl transferase-mediated biotinylated UTP nick end labeling (TUNEL) as- says using in situ cell death detection kit per the manufacturer's instructions (Roche).

Fundus examination, angiography, and optical coherence tomography imaging. Experimental mice were anesthetized, subjected to pupillary dilation with topical $0.5 \%$ tropicamide and $1 \%$ cyclopentolate hydrochloride, and photographed with a customized fundus imaging system (Paques et al., 2007). Briefly, we connected a 5-cm-long tele-otoscope (1218AA; Karl Storz) and digital camera (D80; Nikon) with an additional +5.00 magnifying lens. A xenon lamp (201315-20; Karl Storz) connected through an optic fiber to the tele-otoscope was used as the light source. Fundus angiography was performed following intraperitoneal injection of fluorescein and imaged with Micron II Rodent Fundus Imaging System (Phoenix Research Labs), equipped with a 390-490 nm excitation filter and a $500 \mathrm{~nm}$ long-pass emission filter. Still-frame images and video-rate sequences were acquired with Streampix III image acquisition software (NorPix). Ultra-high-resolution spectral-domain optical coherence tomography (SD-OCT) imaging (Bioptigen) was used to obtain cross-sectional views of the retina in vivo (right eye). Four individual B-scan images were averaged to generate a final image for analysis.

Flat-mount analyses of microglia and retinal pigment epithelium cells. $\mathrm{Nrl}^{-1-}$ mice (from 2 weeks to 11 months) were killed by $\mathrm{CO}_{2}$ asphyxiation and enucleated. The globes were fixed in $4 \%$ paraformaldehyde overnight, rinsed in PBS, and then incubated in a buffer containing $1 \times$ PBS, $0.5 \%$ BSA, $0.2 \%$ Tween $20,0.05 \%$ sodium azide, at $\mathrm{pH} 7.3$. Retinal and sclerochoroidal tissues were dissected intact from the globe, flatmounted, and processed for immunohistochemistry. Sclerochoroidal flat mounts [with the retinal pigment epithelium (RPE) layer upper- 


\section{A Brn3a / NF-L}
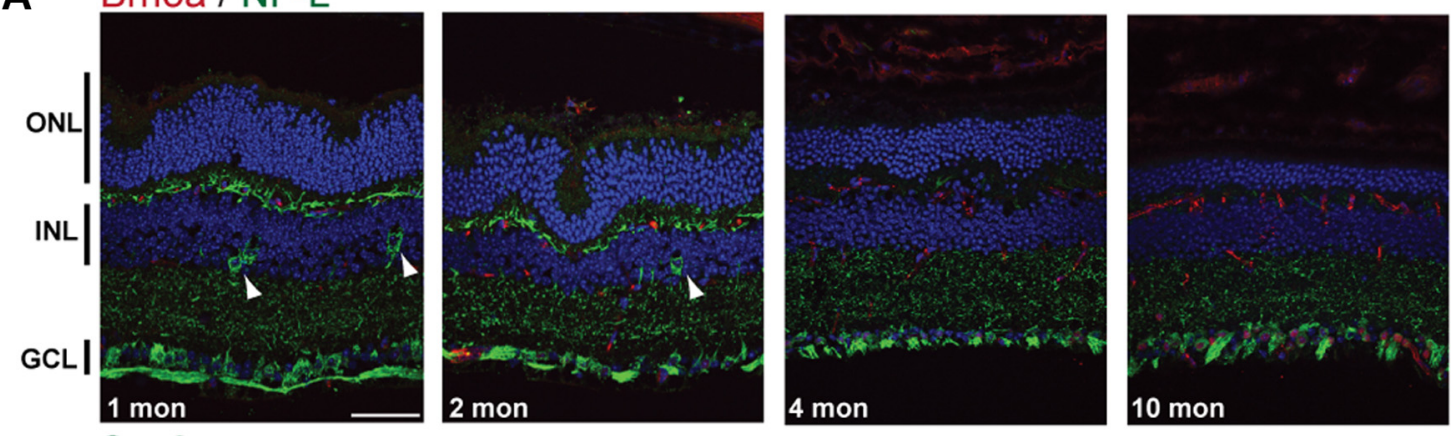

B
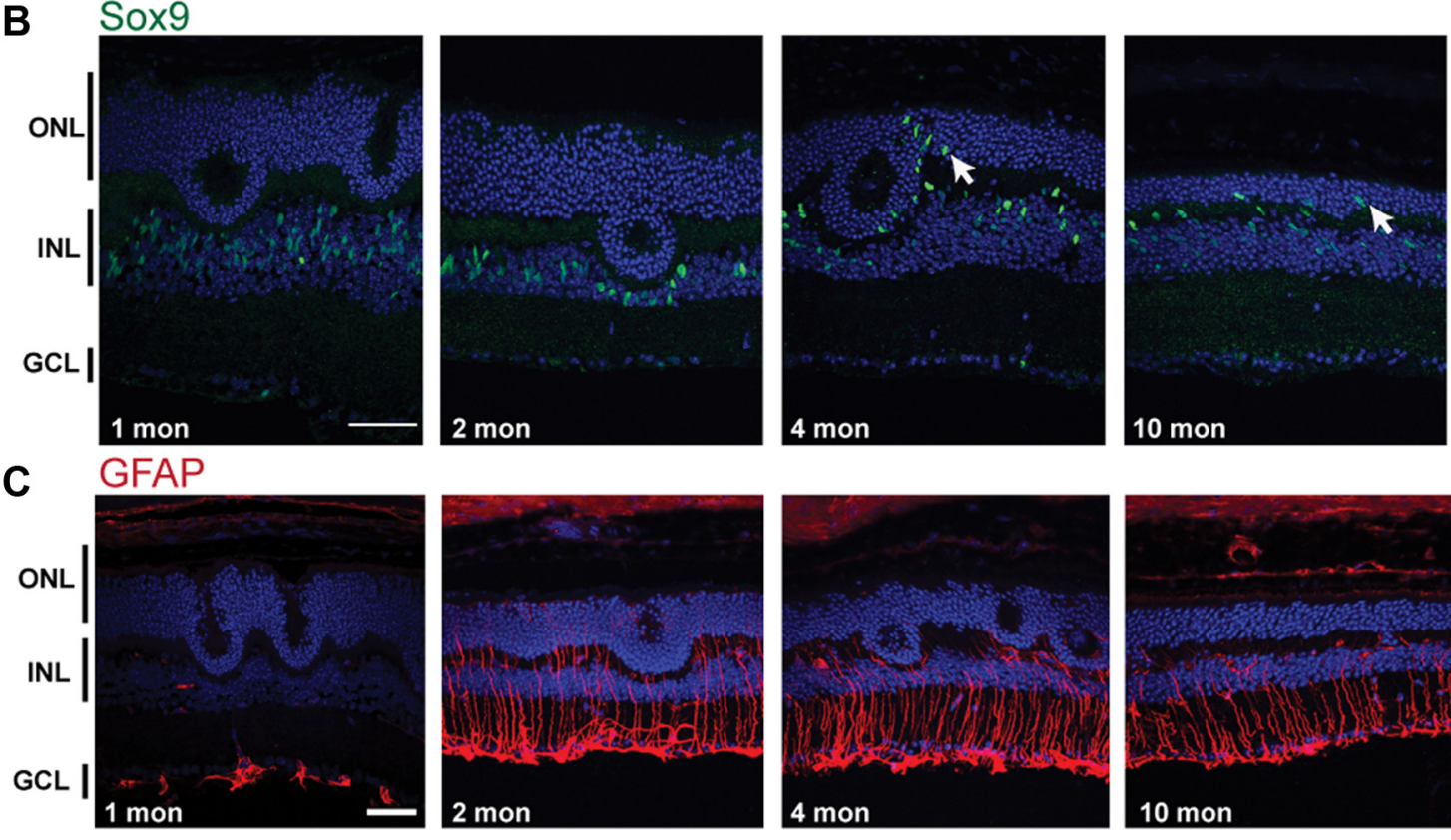

Figure 3. Altered cell types in $1,2,4$, and 10 month $\mathrm{Nrl}^{-/-}$retina. $A$, Ganglion cells were immunolabeled with anti-Brn3a (red) and anti NF-L (green) and showed presence of displaced ganglion cells in the INL of young animal (1 and 2 months of age). These were not present in 4- and 10-month-old animals. $\boldsymbol{B}$, Müller cells, immunolabeled with anti-Sox9 antibody (green), migrated first around the remaining pseudorosettes (at 4 months), and then in the entire onl (10 months). C, GFAP immunolabeling (red) showed strong activation of Müller cells at 2, 4, and 10 months of age.

most] were used for analysis of microglia and RPE cell morphology and distribution. Retinal flat mounts were used to analyze the organization of photoreceptors and ganglion cells. Separately fixed eyecups from $\mathrm{Nrl}^{-1-}$ mice were embedded in $7 \%$ agarose and $100-\mu$ m-thick retinal sections prepared using a vibratome (Leica VT1000S).

Electroretinography. Electroretinography (ERG) was performed as previously described (Pang et al., 2005). Only photopic ERGs were recorded since $\mathrm{Nrl}^{-1-}$ mice have a cone-only retina (Mears et al., 2001).

Malondialdehyde assay. Thiobarbituric acid reactive substances (TBAR) assay kit (Cayman Chemical) was used to measure the concentration of malondialdehyde (MDA), a product of lipid peroxidation. For each condition, five retinas were used in two independent experiments for TBAR assays and processed according to the manufacturer's instructions.

$R N A$ isolation. For microarray analysis, frozen $\mathrm{Nrl}^{-1-}$ mouse retinas from four biological replicates at 1, 2, 4, 6, and 10 months of age were lysed with a mortar and pestle in RLT buffer containing DTT (QIAGEN), followed by a QiaShredder column (QIAGEN). RNA was isolated using the RNeasy Mini Kit using an on-column DNase procedure with RnaseFree DNase (QIAGEN). For whole-transcriptome sequencing, frozen $\mathrm{Nrl}^{-1-}$ mouse retinas from 1,2, and 4 months of age were lysed with a mortar and pestle in Trizol reagent (Invitrogen). RNA quality and quantity were assessed using RNA 6000 Nano Kit (Agilent).

Microarray hybridization. Ribosomal reduction reactions were performed on total RNA $(1 \mu \mathrm{g})$ from each sample using the RiboMinus Kit (Invitrogen). rRNA reduced RNA was used for sense target construction using the GeneChip Whole Transcript Sense Target Labeling Assay kit (Affymetrix) per the manufacturer's protocol. Sense targets were hybridized to GeneChip Mouse Exon 1.0 ST arrays (Affymetrix), processed per manufacturer's instructions, and scanned on a GC Scanner 3000 7G running AGCC (Affymetrix) for .CEL file generation.

Microarray data analysis. The values of individual probes belonging to one probe set (four probes/set in $90 \%$ of the cases) were averaged and normalized using Partek Genomics Suite 6.5 (Partek). The average fluorescence intensity was calculated for annotated genes using the RMA (robust multichip average) algorithm. The updated mapping files were downloaded from the web site of Affymetrix and core meta-probe set list having strong annotation support (e.g., from RefSeq and other GenBank alignments of "complete CDS" transcripts) was used for further analysis. One-way ANOVA was performed to identify differentially expressed genes. To correct for false positives, we used the Benjamini-Hochberg false discovery rate (FDR) procedure with a minimum value of $p \leq 0.05$. Only genes showing a greater than twofold change with respect to 1 month expression data were considered for further analysis.

Whole-transcriptome sequencing (RNAseq). Transcriptome libraries were constructed using $1 \mu \mathrm{g}$ of total RNA with the mRNA-seq sample preparation kit (Illumina), according to the manufacturer's protocols with only minor modifications. Briefly, ligated library DNA were electrophoresed on a $2 \%$ agarose gel and stained with SYBR Gold. The $200 \mathrm{bp}$ band was isolated using a $1 \mathrm{~mm}$ GeneCatcher (Gel Company), and DNA recovered using QIAquick Gel Extraction kit (QIAGEN). The library DNA was quantitated using DNA-1000 kit (Agilent). Single-read cluster 
generation of $10 \mathrm{pm}$ libraries was performed using the Single-Read Cluster Generation kit, version 4 (Illumina). Sequence-by-synthesis of 76 base length was performed on a Genetic Analyzer IIx running SCS2.6 (Illumina).

RNAseq data analysis. Raw sequence reads were mapped onto the University of California, Santa Cruz, mm9 mouse genome using the public domain Efficient Large-Scale Alignment of Nucleotide Database (ELAND). These data were analyzed with Partek software (Partek) and normalized using the method that calculated reads per $1 \mathrm{~kb}$ of exon model per million mapped reads (RPKM) (Marioni et al., 2008). RefSeq transcripts database (http:// www.ncbi.nlm.nih.gov/RefSeq/) was used to map the sequence reads to the mouse genome. One-way ANOVA analysis was performed to identify differentially expressed genes.

\section{Results}

Transient cone photoreceptor cell death in $\mathrm{Nrl}^{-/-}$mouse retina

Fundus examination of the $\mathrm{Nrl}^{-1-}$ mice revealed abnormalities with age (Fig. $1 A$ ). White spots were observed in 1-monthold $\mathrm{Nrl}^{-1-}$ but not in age-matched wildtype (WT) C57BL/6 mouse retina; these white lesions correspond in size and location to whorls and rosettes reported in the outer nuclear layer (ONL) of $\mathrm{Nrl}^{-1-}$ retina (Mears et al., 2001; Daniele et al., 2005; Oh et al., 2007). In addition, an accumulation of pigmentary abnormalities and increased attenuation of the retinal vessels were observed in 2-month-old $\mathrm{Nrl}^{-1-}$ mice. At 6 months, papillary atrophy was evident, suggesting optic nerve or retinal ganglion cell loss (Fig. 1A).

As previously described (Mears et al., 2001; Daniele et al., 2005), photopic ERG recordings (corresponding to cone function) in $\mathrm{Nrl}^{-1-}$ mice at 1 and 2 months of age showed supranormal amplitudes for both a- and b-wave (Fig. $1 B, C$ ). However, repeated recordings at different ages between 1 and 4 months demonstrated a drastic reduction in the mean a-wave amplitude, from $50.6 \pm 1.1 \mu \mathrm{V}$ at 1 month to $16 \pm 2.4 \mu \mathrm{V}$ at 4 months of age (Fig. $1 C$ ). The b-wave amplitudes at maximum light stimulation were relatively stable between 1 and 2 months $(189 \pm 11$ and $179 \pm 19 \mu \mathrm{V}$, respectively) (Fig. $1 B, C$ ), but decreased significantly (to $109 \pm 9 \mu \mathrm{V}$ ) by 4 months. Histological analysis in methacrylate sections of the $\mathrm{Nrl}^{-1-}$ retina demonstrated massive photoreceptor cell loss retina between 2 and 4 months of age (Fig. $1 D$ ). During this period, the ONL decreased in thickness from 8 to 10 rows of nuclei to approximately 4 rows. Interestingly, ONL thickness remained relatively stable (two to four rows) at 6 months and later. However, at 10 months, the ganglion cell layer (GCL) showed progressive thinning compared with younger $\mathrm{Nrl}^{-1-}$ mice (Fig. $1 \mathrm{D}$ ), suggesting a cause for optic atrophy observed by fundoscopy at this age (Fig. 1A). Even in 18-month-old mice, the thickness of the ONL was unchanged (two to four rows of nuclei) (data not shown), indicating that the complete absence of rod photoreceptors in $\mathrm{Nrl}^{-1-}$ mouse retina did not lead to further loss of cones.

4

mon
Ventral
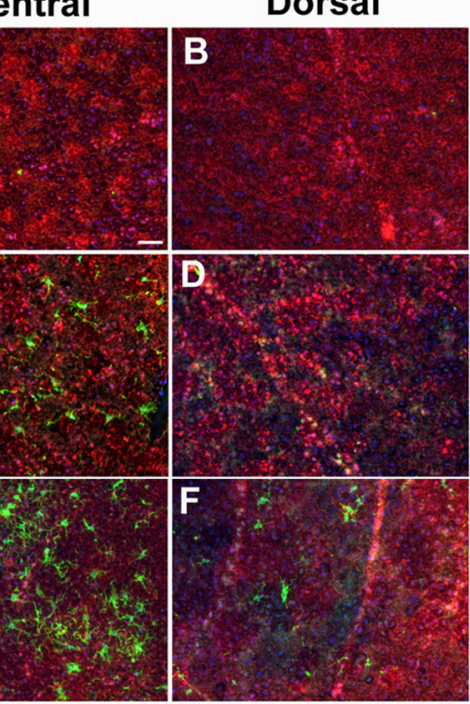

Figure 4. Migration of retinal microglia into the outer retina during the period of photoreceptor degeneration. Microglia months, with larger numbers accumulating in the ventral quadrant compared with the dorsal quadrant. RPE cell density and morphology are not significantly changed during this period. $\mathbf{L}-\mathbf{N}$, Cross-sectional views of microglia distribution in vibratome sections of the retina at different ages. At 2 months $(\boldsymbol{M})$, microglia are closely associated with photoreceptor rosette structures (arrow) and also in the subretinal space (arrowheads). At 4 months $(\boldsymbol{N})$, microglial density in the outer retina decreases as the photoreceptor pseudorosettes resolve and disappear. Scale bars, $50 \mu \mathrm{m}$.

Transmission electron microscopy images of $\mathrm{Nrl}^{-1-}$ mouse retina in the dorsal-ventral midline plane and in the dorsocentral retina demonstrated the presence of short OSs at 1 month of age (Fig. 1E). While regular stacks of OS discs were present, they did not elongate as in WT mice, and some areas of abnormal membrane vesicle formation were observed (Fig. $1 E$, asterisks). By 4 months, OSs have progressive shortened such that the distinction between OS and inner segment (IS) could no longer be discerned. In addition, abnormal accumulation of IS material appeared in the ONL at 10 months. Membrane stacks corresponding to RPE apical microvilli (as identified by their position, spacing, and length) were also observed (Fig. 1E).

Optical coherence tomography (OCT) imaging in 1-monthold live animals showed broad areas of shallow retinal detachment from the RPE, distinct from the pseudorosettes located in the ONL (Fig. 1F). These detachments were detected both in the center and the periphery of the retina without a preferential locus of occurrence. However, all areas of retinal detachment had resolved at 4 months of age. By OCT Doppler imaging, large retinal blood vessels of 2- and 10-month-old $\mathrm{Nrl}^{-1-}$ mice had increased cross-sectional areas (Fig. $1 F$ ) compared with WT mice. 
A
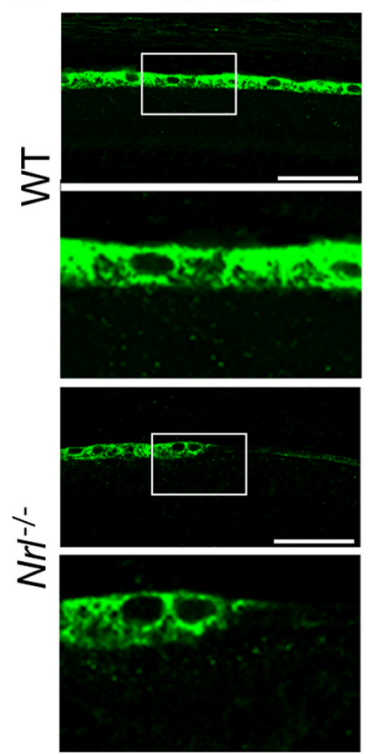

B
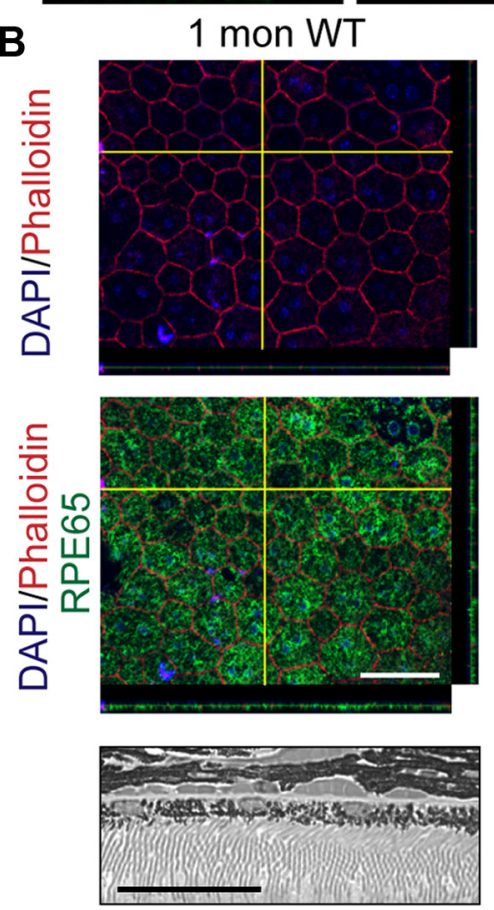

PNA
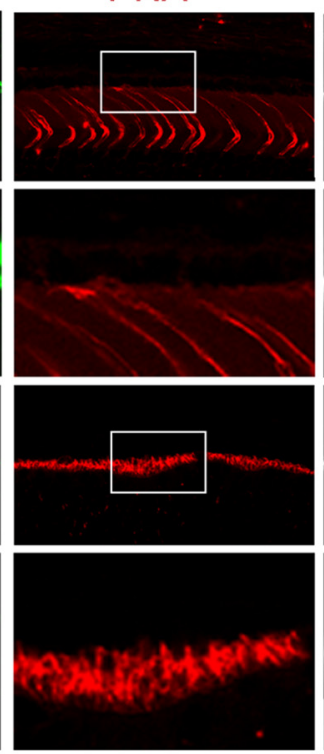

1 mon $\mathrm{Nr}^{-1-}$
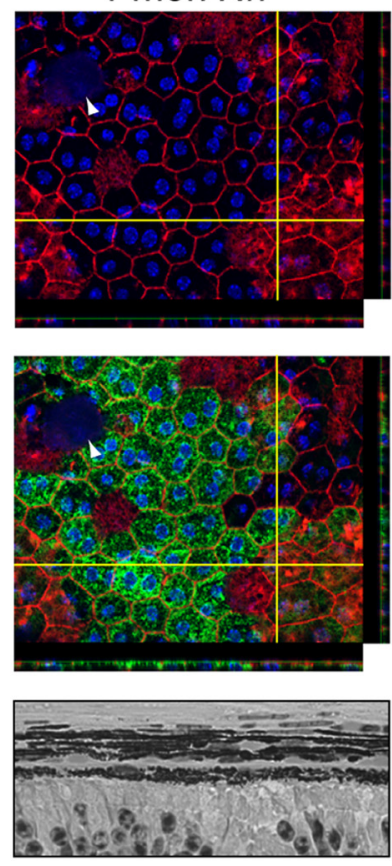

Ezrin
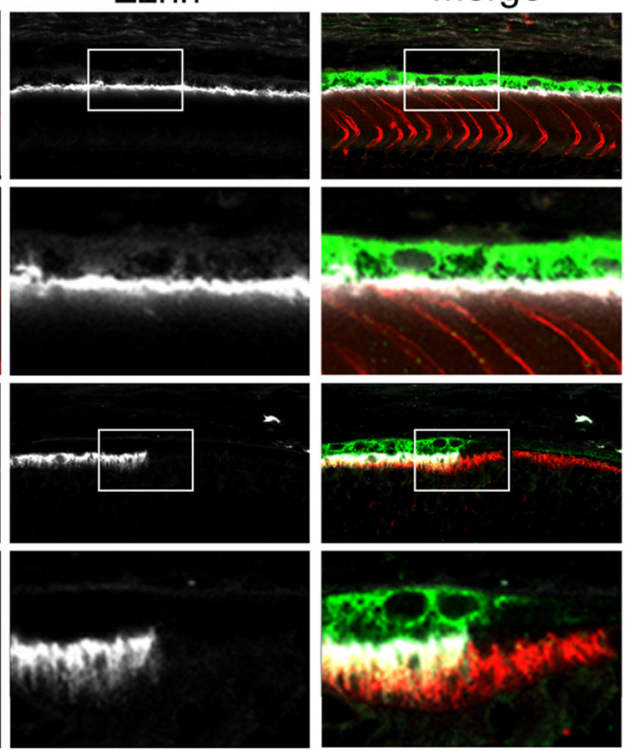

10 mon $\mathrm{Nr}^{-1-}$
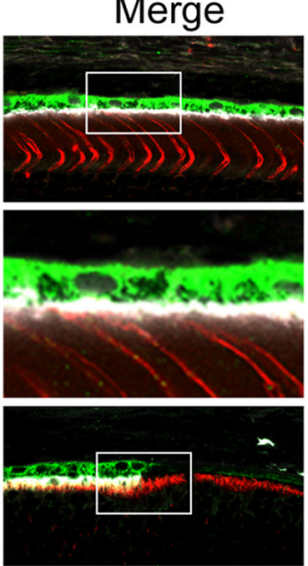
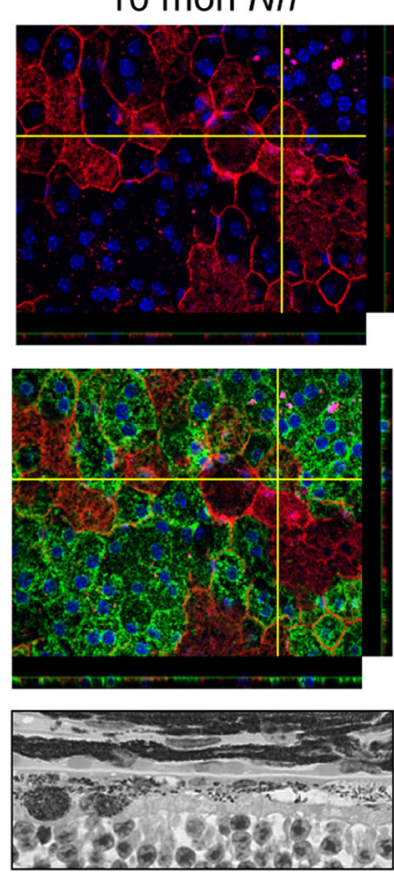

Figure 5. Changes in RPE in $\mathrm{Nrl}^{-/-}$retina. A, Immunolabeling on vibratome sections of RPE with anti-RPE65 (green), cones with PNA (red), and RPE apical side with anti-Ezrin (gray) on 4-month-old WT and $\mathrm{Nrl}^{-/-}$mouse retina showed weaker RPE65 expression and absence of ezrin in front of cone photoreceptors in Nrl ${ }^{-1-}$ mice compared with WT mice. Scale bar, $40 \mu \mathrm{m}$. $\boldsymbol{B}$, Top, RPE-sclerochoroidal whole mount of 1 month WT mice and 1- and 10-month-old Nrl ${ }^{-1-}$ mice after immunolabeling of RPE cellular outlines stained with Phalloidin (red) and anti-RPE65 (green). Compared with RPE from WT mice, RPE from $\mathrm{Nrl}^{-1-}$ mice showed abnormalities in their junctions with presence of large patches positive for phalloidin. Nuclei are visualized by DAPI staining. The arrowhead indicates apoptotic bodies. If in WT mice, RPE65 showed homogenous expression all RPE cells, in contrast RPE65 expressions were absent in a large number of RPE cells and even among the cells with phalloidin staining in their cell body. Bottom, High magnification of methacrylate sections followed by H\&E staining showed a loss of RPE cells in aged (10 month) $\mathrm{NrI}^{-\prime-}$ retina. Scale bar, $20 \mu \mathrm{m}$.

Preservation of S-cones and M-cones following the period of retinal cell death in the $\mathrm{Nrl}^{-/-}$retina

Immunolabeling with peanut agglutinin (PNA), a marker of cone extracellular matrix, in 1-month-old $\mathrm{Nrl}^{-1-}$ mice showed prominent colocalization with whorls and rosettes that were previously noted in $\mathrm{Nrl}^{-1-}$ and $\mathrm{rd}$ 7 mice (Fig. 2A) (Akhmedov et al., 2000; Mears et al., 2001). The PNA-stained rosette structures in the retina decreased drastically in number from $968 \pm 41$ per retina at 1 month to $141 \pm 16$ per retina at 4 months, and were completely absent at 10 months. However, PNA-positive staining continued to be present in the distal cone segments at all ages, indicating a persistence of the cone extracellular matrix in that location (Fig. 2A,B). S-opsin, M-opsin, and cone arrestin were also uniformly expressed at all ages (Fig. 2C). Interestingly, $\mathrm{M}$-opsin was relocalized in the IS in old mice in contrast with its presence in the ONL observed in younger animals. The counting of TUNEL-positive cells confirmed that most cones underwent apoptosis between 2 and 4 months (Fig. 2D). We did not observe significant differences in the repartition of the TUNEL-positive cells between areas of retinal detachments and rosettes. However, 
the cell death in the rosettes could be due to the lack of contact of cone outer segments with RPE, as suggested in a previous study (Daniele et al., 2005). Surprisingly, a significant number of apoptotic cells were also detected in the inner nuclear layer (INL) and GCL. Thus, a majority of cell death in $\mathrm{Nrl}^{-1-}$ retina is transitory during the first 4 months of life and occurs in all retinal layers.

\section{Alterations in ganglion and Müller cells in $\mathrm{Nrl}^{-/-}$retina \\ As cell death was detected in all neuronal layers, we examined the markers for dif- ferent retinal cell types in $\mathrm{Nrl}^{-1-}$ mice. We observed the expression of Brn3a and NF-L, two ganglion cell markers, in the INL of 1 - and 2-month-old $\mathrm{Nrl}^{-1-}$ retina (Fig. $3 A$ ), suggesting the abnormal loca- tion of displaced retinal ganglion cells. In- terestingly, a fraction of the Sox9-positive} Müller cell nuclei were also displaced to the ONL at 4 months (Fig. 3B). Notably, Müller cells showed an evidence of gliosis (as revealed by GFAP immunostaining) as early as 1 month (Fig. 3C) when cell death is initiated.

Since microglial cell activation is reported in many neurodegenerative diseases and models of retinal degeneration (Hanisch and Kettenmann, 2007; Langmann, 2007), we assessed changes in microglial morphology and distribution in $\mathrm{Nrl}^{-1-}$ mice during the period of transitory cell death and with age (Fig. 4). At 2 weeks of age, retinal microglia (as indicated by labeling with Iba1 immunostaining) demonstrated ramified morphologies and a typical distribution [i.e., in the GCL, inner plexiform layer (IPL), and outer plexiform layer (OPL), and were excluded from the outer retina and subretinal space] in $\mathrm{Nrl}^{-1-}$ retina, similar to those in WT mice. By 3 weeks, a few microglial cells in the ventral retina could be seen migrating into the subretinal space coming into contact with RPE, and assuming more rounded and less ramified morphologies, consistent with an activated status (Fig. $4 C$ ). The influx of microglia into the outer retina and subretinal space increased with age, peaking at 2 months (Fig. $4 K, M$ ), exhibiting close association with cone photoreceptor OS including those located in pseudorosettes (Fig. $4 M$ ). Beginning at 4 months of age, a progressive decrease was detected in the number of microglia in the subretinal space (Fig. $4 K$ ), with a resumption of microglia distribution to OPL, IPL, and GCL (Fig. 4N). Microglia appeared to be recruited to the areas of cone degeneration early in the process, before extensive cone loss, and returned to a typical inner retinal distribution after the transitory phase of retinal cell death.

\section{Absence of rod photoreceptor affects RPE integrity, retinal vasculature, and ganglion cell survival}

As interaction of the RPE with photoreceptors is essential for visual function, we investigated the contact of these two layers on $100-\mu \mathrm{m}$-thick vibratome sections (Fig. $5 A$ ) and RPE integrity in sclerochoroidal flat mounts (Fig. 5B). In the RPE layer of WT mice, RPE65, a key enzyme of the visual cycle, could be immunolocalized to the cytoplasm of all RPE cells, while ezrin was detected in the apical RPE cell surface. In $\mathrm{Nrl}^{-1-}$ retina, despite continuous PNA localization in the cones, expression of RPE65 and ezrin was absent in some regions of the RPE monolayer,
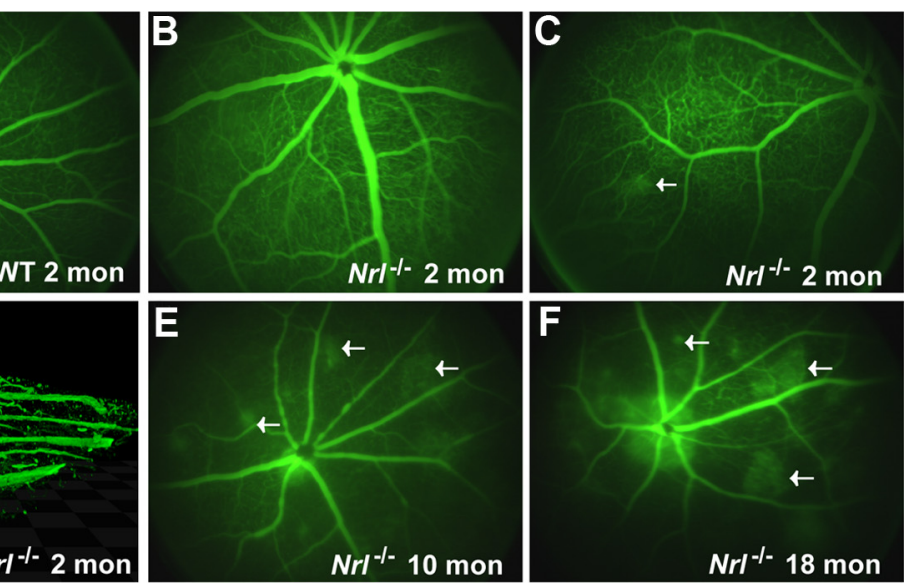
$\mathrm{rl}^{-1-}$ retina. $\boldsymbol{A}-\boldsymbol{C}, \boldsymbol{E}, \boldsymbol{F}$, Angiography after
mice at 2 months $(\boldsymbol{B}, \boldsymbol{C}), 10$ months $(\boldsymbol{E})$, and 18 f the area of leakage during aging. $D$, Three2-month-old $\mathrm{Nrl}^{-1-}$ mice after injection of the blood vessels in the ganglion cell layer.

suggesting a patchy loss of RPE cell function. As early as 1 month of age, we could identify abnormalities in the RPE mosaic (revealed by phalloidin immunolabeling) of $\mathrm{Nrl}^{-1-}$ retina. Some cells did not express RPE65, and others showed internal staining with phalloidin in the focal plane, which likely corresponded to the microvilli. By 10 months of age, the RPE integrity appeared to be disrupted, as shown by the presence of some pyknotic nuclei and loss of junctions between RPE cells (Fig. 5B). Our data are consistent with a recent report demonstrating defective phagocytosis in RPE from $\mathrm{Nrl}^{-1-}$ retina (Mustafi et al., 2011).

We also evaluated the structure and permeability of the retinal vasculature using fluorescein angiography. Two-monthold $\mathrm{Nrl}^{-1-}$ mice demonstrated dilated retinal vessels and also a denser network of retinal capillaries (Fig. 6B), supporting the observations made by OCT imaging (Fig. $1 F$ ). Some abnormal retinal capillary permeability was also found, as evidenced by mild leakage of fluorescein in the retinal periphery (Fig. 6C). A $3 \mathrm{D}$ reconstruction from flat mount retina of 2 -month-old $\mathrm{Nrl}^{-1-}$ mice after dextran-fluorescein injection demonstrated that the leakage observed by angiography came in part from blood vessels present on the internal retinal ganglion cell layer side (Fig. 6D). This observation was confirmed in 5-month-old $\mathrm{Nrl}^{-1-}$ retina (data not shown). With increasing age, the retinal vessels showed a converse luminal narrowing and an increasing extent of fluorescein leakage (Fig. 6E,F).

As GFAP-expressing astrocytes in the GCL have a close relationship with the retinal vasculature (Gariano et al., 1996; West et al., 2005), we evaluated the effects of retinal degeneration on vasculature integrity using flat-mount retina (Fig. 7). We observed a profound change in both large arteries and capillaries in 18-month-old $\mathrm{Nrl}^{-1-}$ retina that in part explained the massive blood leakage detected by angiography (Fig. 7).

In parallel, we immunolabeled ganglion cells on flat-mount retina with anti-Brn3a, a transcription factor specifically expressed in ganglion cells. Consistently, the expression level of Brn3a was lower in $\mathrm{Nrl}^{-1-}$ retina compared with WT (Fig. 7). Thus, if ganglion cells were still present in the central retina of 18-month-old $\mathrm{Nrl}^{-1-}$ mice, they would have low Brn3a expression levels. In contrast, only few ganglion cells were detected at the periphery of the retina, confirming the death of ganglion cells as indicated (Figs. $1 A, D, 3 A$ ). Interestingly, we also observed an 


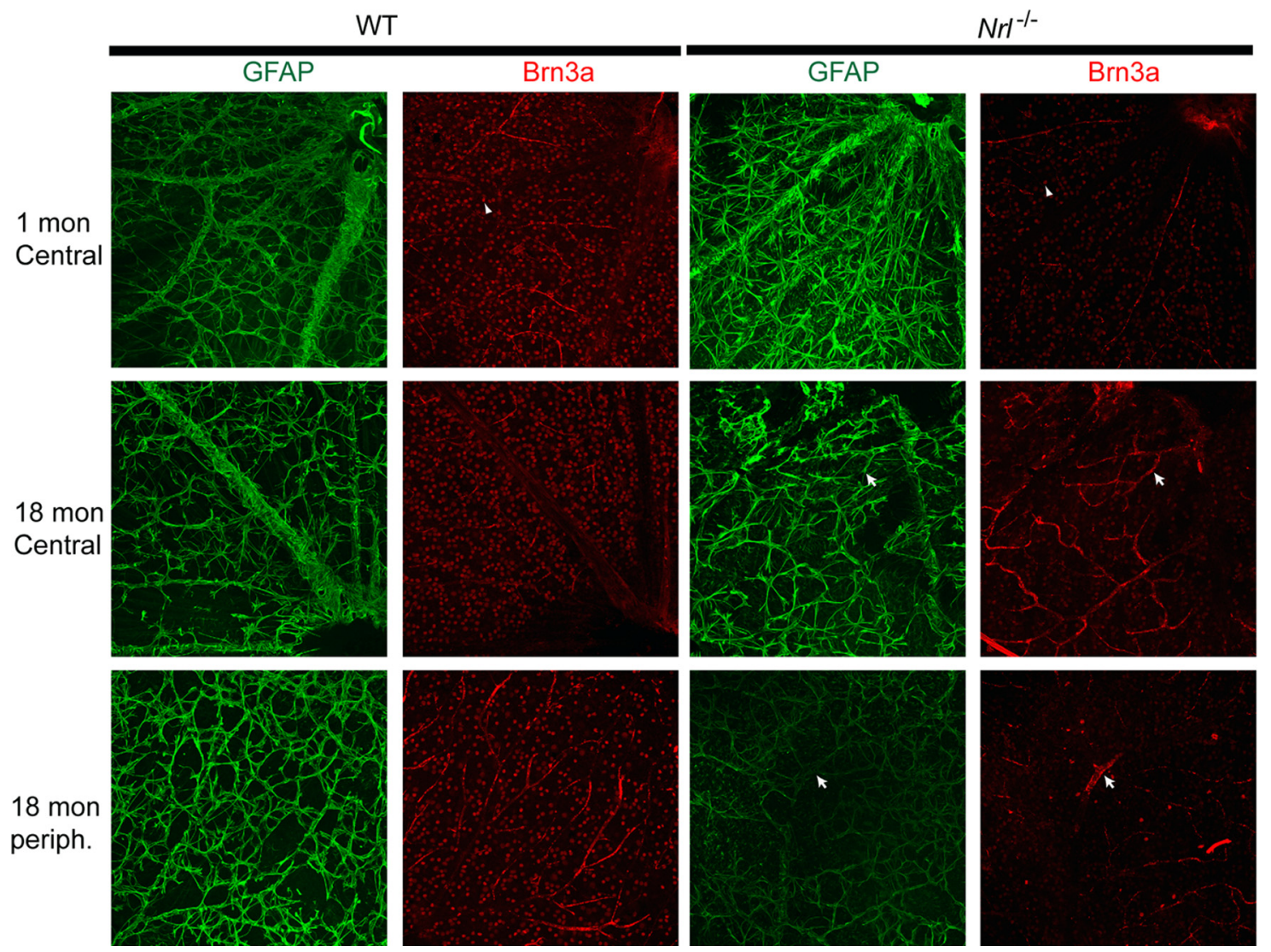

Figure 7. Age-associated alterations of the superficial retinal vasculature and ganglion cell death in $\mathrm{Nrl}^{-1-}$ retina. Immunohistochemistry on whole-flat-mount retina with anti-GFAP (green) and anti-Brn3a (red) antibodies labeling astrocytes, activated Müller cells, and ganglion cells, respectively. GFAP-positive cells aligning blood vessels on the ganglion cell layer side showed profound disorganization of the retinal vasculature, with large areas with no staining in 18-month-old $\mathrm{Nrl}^{-1-}$ mice compared with WT control. Presence of ganglion cells was assessed with anti-Brn3a immunolabeling. $\mathrm{Nrl}^{-1-}$ retina did not show high level of Brn3a expression at all time points. Loss of ganglion cells occurred in 18-month-old $\mathrm{Nrl}^{-/-}$mice but was more pronounced at the periphery compared with central retina.

increase in small capillaries, as revealed by the secondary antimouse IgG that binds to the endogenous IgG in the blood contained in mouse retinal capillaries.

Our findings reveal that transitory cone cell death in $\mathrm{Nrl}^{-/-}$ mice appears to cause profound changes in the retina, including RPE cell death, changes in the retinal vasculature, ganglion cell death, and fluid leakage from the superficial blood vessels on the inner retinal ganglion cell side. However, loss of RPE might also disrupt the retinal blood barrier, resulting in fluid leakage from the choroid side.

\section{Oxidative stress associated with retinal cell degeneration in} $\mathrm{Nrl}^{-1-}$ mice

The oxygen stress in $\mathrm{Nrl}^{-1-}$ mouse retina is predicted to be higher than in WT as illustrated by the fact that the overall photoreceptor circulating current in the $\mathrm{Nrl}^{-1-}$ cones at 1 month (when cones are still healthy) is roughly one-third that of WT (as reflected by the saturated a-wave amplitude), and therefore the outer retina of the $\mathrm{Nrl}^{-1-}$ mice will require only approximately one-third as much oxygen supplied by the choroid, leading to elevated oxygen tension (Daniele et al., 2005). We therefore investigated the oxidative stress in $\mathrm{Nrl}^{-1-}$ retina by assessing the presence of acrolein, a toxic product formed by lipid peroxidation (Fig. 8A). While staining for acrolein was absent in 1 -month-old retina, prominent staining was observed at 2 months, particularly in the GCL and around the whorls and rosettes of the ONL, before decreasing in overall intensity at 10 months. We also measured the concentration of MDA, a marker of oxidative stress, in $\mathrm{Nrl}^{-1-}$ and WT retinas at different ages. In $\mathrm{Nrl}^{-1-}$ retinas, levels of MDA were low and similar to those found in WT retinas at 1 month, but increased to a peak at 4 months (2.5-fold increase) before decreasing at 10 months (Fig. $8 \mathrm{~B}$ ). However, we noticed that the peak of MDA is delayed with significant cone cell loss occurring between 2 and 4 months of age. The concordance between increased acrolein staining and MDA levels at this age implicates a role of oxidative stress in the cone cell death.

\section{Changes in gene expression profile during cone cell death in} $\mathrm{Nrl}^{-1-}$ retina

To gain insights into cellular pathways underlying transitory cone death in $\mathrm{Nrl}^{-1-}$ retina, we performed microarray analysis of four biological replicates at five different time points $(1,2,4,6$, and 10 months). We compared 2, 4, 6, and 10 month microarray data to 1 month, when all cones are still present, and selected a minimum twofold change (FC) cutoff for further analysis. The data revealed statistically significant differences $(p \leq 0.05)$ for 350 mapped genes in at least one of the four comparisons (data not shown). As most cone death occurs between 1 and 4 months of age in $\mathrm{Nrl}^{-1-}$ retina, we grouped together genes with $\mathrm{FC} \geq 2$ at 2 or 4 months and those differentially expressed at 6 or 10 months with respect to 1 month. At 6 or 10 months, 337 genes were significantly differentially expressed compared with 1 month and 88 at 2 or 4 months compared with 1 month. The fact that the vast 


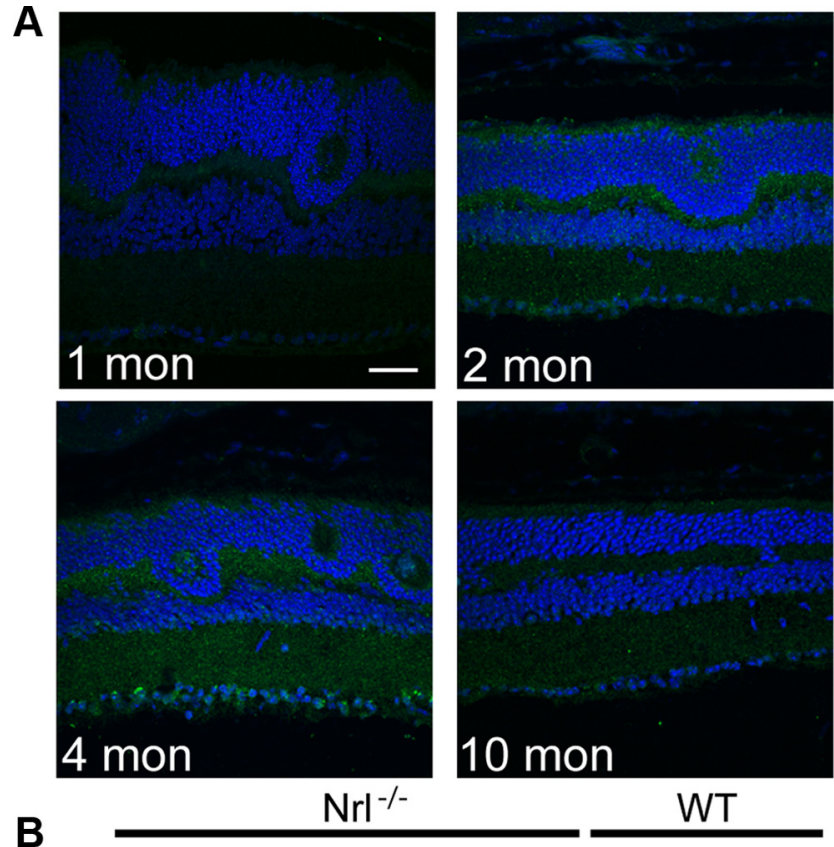

B

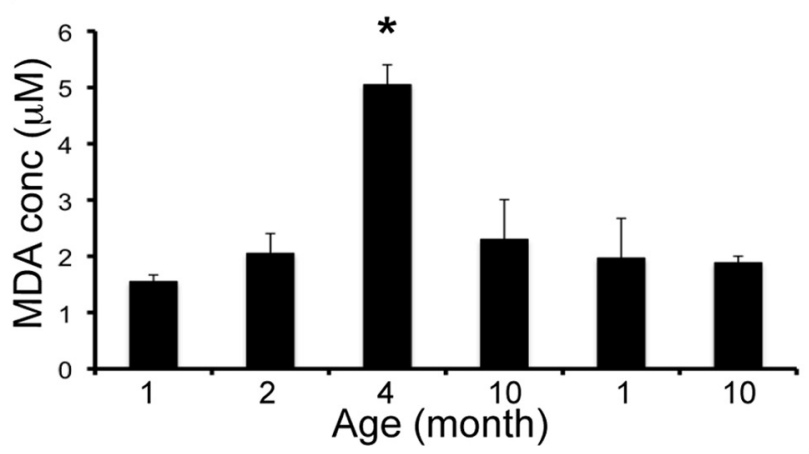

Figure 8. Lipid peroxidation in $\mathrm{Nr}^{-1-}$ retina. $\boldsymbol{A}$, Immunolabeling of acrolein (green), a toxic product formed from lipid peroxidation and used as a marker of oxidative stress, was increased at 2 and 4 months in $\mathrm{Nrl}^{-1-}$ mice, relative to 1 and 10 months. Scale bar, $20 \mu \mathrm{m}$. $\boldsymbol{B}$, Thiobarbituric acid-reactive substances assay was used to assess lipid peroxidation in retinal lysates of 1-, 2-, 4-, 10-month-old $\mathrm{Nrl}^{-1-}$ mice and of 1- and 10-month-old WT mice. The assay shows a significant increase of MDA in 4-month-old $\mathrm{Nrl}^{-1-}$ mouse retina. Error bars indicate \pm SD. Standard $t$ test was used to determine significance. ${ }^{*} p<0.05$.

majority of genes are differentially expressed at 6 or 10 months might reflect the remodeling of the retina after a period of transitory cone cell death. We then focused on 88 genes that are potentially involved in cone cell death and exhibit FC $>2$. Statistically significant downregulation was detected for 53 genes with an average fold change (AFC) of -2.4 and -2.6 at 2 and 4 months, respectively (Fig. 9A). Thirty-five genes with statistically significant upregulation demonstrated AFC of 2.2 and 2.5 at 2 and 4 months, respectively (Fig. 9B).

Meta-analysis of biological functions of 88 differentially expressed genes at 2 and 4 months compared with 1 month identified three major categories - immune response, signal transduction, and stress response (Fig. 9C). Among these, crystallins correspond to a large family of chaperones involved in response to stress and inflammation, and their expression is increased in several retinal diseases (Fort and Lampi, 2011) including AMD (Umeda et al., 2005), uveitis (Rao et al., 2008), and diabetic retinopathy (Kumar et al., 2005; Fort et al., 2009). Interestingly, Cry $\alpha a, C r y \beta a 1, C r y \beta b 1, C r y \gamma c$, and Cry $\gamma d$ were highly expressed at 1,2 , and 4 months of age in $\mathrm{Nrl}^{-1-}$ retina (Table 1 ). We confirmed their downregulation with age by qPCR (Fig. 9D), corresponding to the transitory cell death. However, crystallin expression is almost undetectable thereafter (6 and 10 months). Cry $\alpha a, C r y \beta a 1$, and Cry $\gamma d$ are among the most highly expressed crystallins between 1 and 4 months, indicating their potential role in cone homeostasis and response to stress.

Only 13 genes were differentially expressed between 1 and 4 months, with no statistically significant expression change between 6 and 10 months compared with 1 month: Cxcl13, Ifit1, Serpina3n, Asf1b, Ctss, Samd7, Ifitm3, Serping1, Cfi, Hnrpdl, Col6a1, Abhdl4a, and Pcbp4. Ingenuity pathways analysis (IPA) revealed that 12 of 13 genes act as hubs with a majority associated with immune response: Cfi, Ctss, Cxcl13, Ifit1, Iftm3, Serpina3n, and Serping1 (Fig. 9E).

We then performed whole-transcriptome analysis by NextGen Sequencing (RNAseq) of 1, 2, and 4 month $\mathrm{Nrl}^{-1-}$ retina and identified 39 genes (Table 1) that were also present in 88 differentially expressed genes revealed by microarray analysis. Network reconstruction with these 39 genes (Fig. 9F) identified $\operatorname{Tnf}$ (tumor necrosis factor) as a central hub for 12 differentially expressed genes, confirming the importance of immune response in cone death observed in $\mathrm{Nrl}^{-1-}$ retina. The presence of Serping1 upregulation is notable as its expression is associated with AMD (Mullins et al., 2009; Lu et al., 2010).

\section{Discussion}

The studies of cone function are critical for elucidating normal visual process and defining pathogenic mechanisms of retinal diseases. Photoreceptors in $\mathrm{Nrl}^{-1-}$ retina share many features with "normal" cones (Daniele et al., 2005), including chromatin clumping, cone matrix sheath, gene expression, mitochondrial length, open discs, and ERG pattern. Here, we report novel aspects of cone biology by comprehensive examination of $\mathrm{Nrl}^{-/-}$ retina, which at $1-4$ months of age shares fundamental features (e.g., photoreceptor degeneration, RPE changes, Müller cell hypertrophy) with rodent models of retinal degeneration and human RP (Milam et al., 1998). The rapid cone cell death in $\mathrm{Nrl}^{-1-}$ retina is similar to what is observed in $P d e 6 b^{-1-}$ and Pde $6 \mathrm{~g}^{-1-}$ mouse retina between 1 and 4 months of age (Punzo et al., 2009). However, unlike rodent and human RP, cone photoreceptor death stabilizes in the $\mathrm{Nrl}^{-1-}$ retina, with a population of cones for the remainder of life. Notably, macular cones, although not functional, are preserved in many RP and Leber congenital amaurosis patients (John et al., 2000; Cideciyan et al., 2007; Jacobson et al., 2010).

An important question is why the cones in the $\mathrm{Nrl}^{-1-}$ retina do not undergo a constant rate of degeneration like their counterparts in the macula of an RP patient? Large areas of retinal detachment, loss of ganglion cells, and altered vasculature in $\mathrm{Nrl}^{-1-}$ retina at a young age indicate neuronal degeneration and remodeling (Milam et al., 1998; Marc et al., 2003). Unlike $\mathrm{Nrl}^{-1-}$ retina, inner retinal neurons are more preserved and send processes into aberrant regions in human RP retina (Stone et al., 1992; Santos et al., 1997; Humayun et al., 1999). The remodeling of synaptic connections between photoreceptors and bipolar cells is also observed in animals carrying rhodopsin or Pdeb mutation (Peng et al., 2000) or after retinal detachment (Lewis et al., 1998). In $\mathrm{Nrl}^{-1-}$ retina, the rod bipolar cells connect to cone terminals in the absence of rods (Strettoi et al., 2004), whereas cone bipolars are connected to rods in the absence of cones in Crxp-Nrl mouse (Oh et al., 2007). The axon and dendritic terminals of horizontal cells are also affected in absence of rod or cone photoreceptors (Raven et al., 2007). 
A

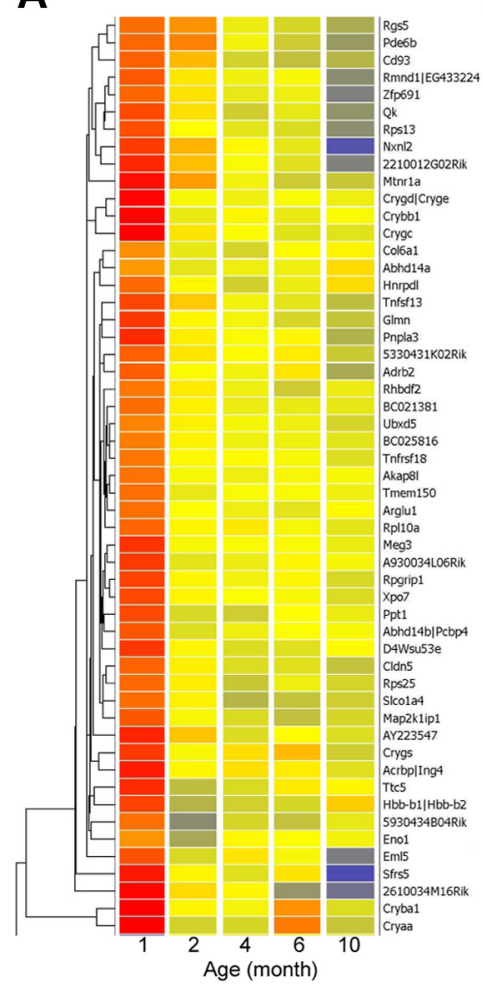

E

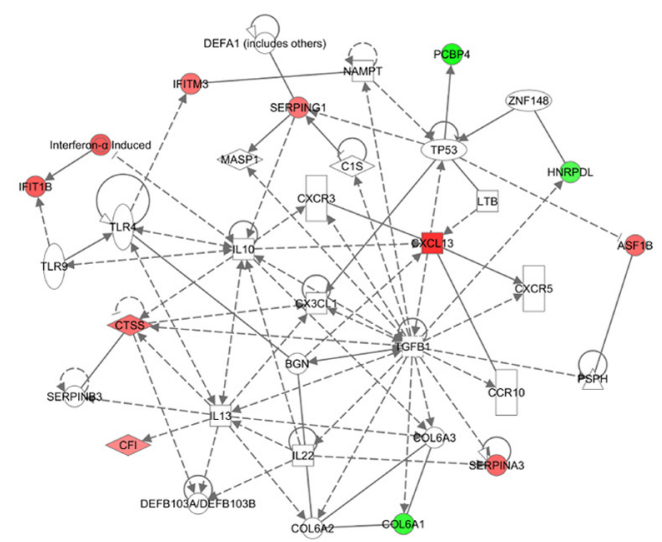

B

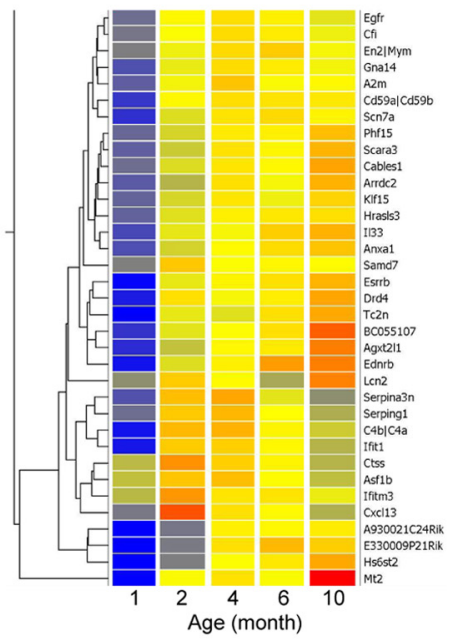

C
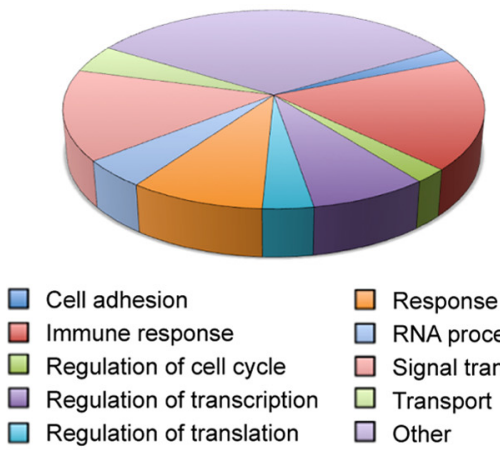

$\square$ Response to stress $\square$ RNA processing $\square$ Signal transduction $\square$ Transport $\square$ Other
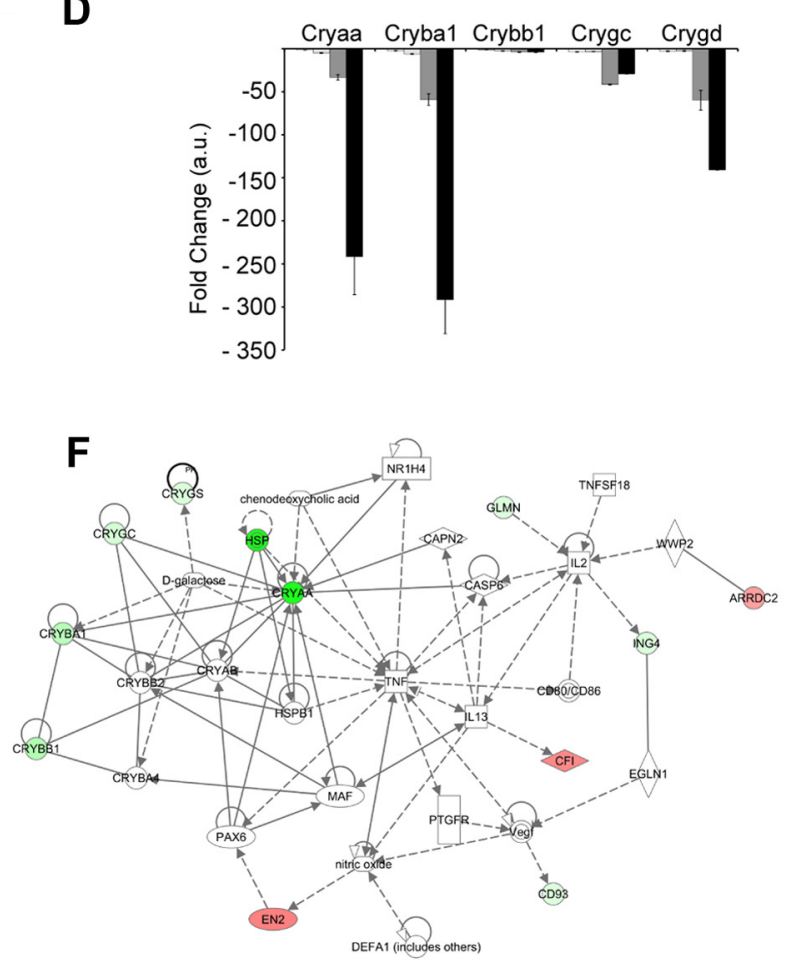

Figure 9. Gene expression analysis of $\mathrm{Nr}^{-1-}$ retina. $\boldsymbol{A}, \boldsymbol{B}$, Hierarchical clustering dendrogram of 350 genes having a FDR $p \leq 0.05$ and a minimum fold change of 2 between 2 or 4 months compared with 1 month. Bright blue indicates lowest signal with increasing expression by yellow to bright red. $C$, Chart pie representation of the main biological function representing 88 genes differentially expressed. D, qRT-PCR validation of Cry $\alpha a$, Cry $\beta a 1, C r y \beta b 1, C r y \gamma c$, and Cry $\gamma d$ using four individual biological replicates at 1, 2, 4, 6, and 10 months. Error bars indicate \pm SEM. $\boldsymbol{E}$, Network reconstruction using IPA with 13 genes having a FDR $p \leq 0.05$ and a minimum fold change of 2 only between 2 or 4 months compared with 1 month. $F$, Network reconstruction using IPA with 39 genes identified as differentially expressed between 2 or 4 months compared with 1 month after comparison with microarray and RNAseq analysis. Red indicates upregulation of the gene of interest at 2 months compared with 1 month; green indicates downregulation of the gene of interest at 2 months compared with 1 month.

Ablation of cones by cone-DTA transgene in $r d 7 / r d 7$ mouse retina, caused by the loss of $\mathrm{Nr} 2 \mathrm{e} 3$ [a transcriptional target of NRL (Oh et al., 2008)] function, reduces Müller cell activation, indicating a contribution of excess cones to pseudorosette formation (Chen and Nathans, 2007). The cone death between 1 and 4 months in $\mathrm{Nrl}^{-1-}$ retina results in complete loss of pseudorosettes without preventing Müller cell activation. We suggest that loss of rosettes in older $\mathrm{Nrl}^{-1-}$ retina allows appropriate positioning of surviving cones with RPE, which can explain the arrest of cone cell death. Notably, prompt surgical reattachment after retinal detachment in humans prevents visual acuity loss and allows vision restoration (Fisher and Lewis, 2003). In monkeys that had detachment/reattachment surgery, the cones degenerate while detached but their OS length partially recovers when reat- tached (Guérin et al., 1989). Retinal detachment in $\mathrm{Nrl}^{-1-}$ retina does not significantly alter S- or L/M-opsin expression, as in a cat model of retinal detachment (Rex et al., 2002). Additionally, formation of glial scar and retinal remodeling (Jones and Marc, 2005; Lewis et al., 2010) are undetectable in $\mathrm{Nrl}^{-1-}$ retina. Experimental retinal detachment (Lewis et al., 2010) leads to proliferation of Müller cells and migration of their cell bodies to ONL. Thus, retinal detachment early in $\mathrm{Nrl}^{-1-}$ retina can partly explain the presence of Müller cell bodies in the ONL and may reflect a consequence of dedifferentiation (Fischer and Reh, 2003; Bernardos et al., 2007; Karl et al., 2008). A few BrdU-positive cells were visible in the ONL of 12-month-old but not 2-month-old $\mathrm{Nrl}^{-1-}$ retina (data not shown). Further investigations are required to delineate the identity of these cells. 
Table 1. Differentially expressed genes at 2 and 4 months compared with 1 month in common between microarray and RNAseq analysis

\begin{tabular}{|c|c|c|c|c|c|c|}
\hline \multirow[b]{2}{*}{ Gene symbol } & \multirow[b]{2}{*}{ RefSeq } & \multirow[b]{2}{*}{ Entrez gene name } & \multicolumn{2}{|l|}{ Microarray } & \multicolumn{2}{|l|}{ RNAseq } \\
\hline & & & FC 2 versus 1 & FC 4 versus 1 & $\mathrm{FC} 2$ versus 1 & FC 4 versus 1 \\
\hline \multicolumn{7}{|c|}{ Immune response } \\
\hline Cxcl13 & NM_018866 & Chemokine (C-X-C motif) ligand 13 & 3.01 & 1.82 & 8.32 & 4.32 \\
\hline $\operatorname{Lc} 2$ & NM_008491 & Lipocalin 2 & 2.24 & 1.73 & 6.90 & 5.93 \\
\hline Ctss & NM_021281 & Cathepsin S & 2.12 & 1.60 & 2.30 & 1.81 \\
\hline Ifitm3 & NM_025378 & Interferon-induced transmembrane protein 3 & 2.07 & 1.43 & 2.60 & 1.39 \\
\hline Serping1 & NM_009776 & Serpin peptidase inhibitor, clade G, member 1 & 2.04 & 2.11 & 3.27 & 2.48 \\
\hline$A 2 m$ & NM_175628 & $\alpha$-2-Macroglobulin & 1.90 & 2.51 & 2.86 & 2.62 \\
\hline Anxa1 & NM_010730 & Annexin A1 & 1.83 & 2.26 & 1.71 & 2.14 \\
\hline $\mathrm{Cfl}$ & NM_007686 & Complement factor I & 1.74 & 2.01 & 3.22 & 2.45 \\
\hline$C d 93$ & NM_010740 & CD93 molecule & -1.52 & -2.01 & -1.61 & -3.10 \\
\hline Tnfsf13 & NM_023517 & Tumor necrosis factor superfamily, member 13 & -1.59 & -2.03 & -2.25 & -2.65 \\
\hline Glmn & NM_133248 & Glomulin, FKBP-associated protein & -2.10 & -2.20 & -1.83 & -2.01 \\
\hline \multicolumn{7}{|c|}{ Signal transduction } \\
\hline Drd4 & NM_007878 & Dopamine receptor $\mathrm{D}_{4}$ & 2.71 & 2.31 & 4.05 & 3.54 \\
\hline Ednrb & NM_007904 & Endothelin receptor type B & 2.36 & 2.75 & 1.85 & 2.79 \\
\hline Egfr & NM_207655 & Epidermal growth factor receptor & 1.93 & 2.15 & 1.84 & 2.47 \\
\hline Gna14 & NM_008137 & Guanine nucleotide binding protein, $\alpha 14$ & 1.83 & 2.40 & 2.56 & 3.08 \\
\hline Arrdc2 & NM_027560 & Arrestin domain containing 2 & 1.39 & 2.10 & 2.51 & 6.47 \\
\hline Pde6b & NM_008806 & Phosphodiesterase 6B, cGMP-specific, rod, $\beta$ & -1.11 & -2.08 & -1.12 & -2.26 \\
\hline Mtnr1a & NM_008639 & Melatonin receptor $1 \mathrm{~A}$ & -1.53 & -2.08 & -1.23 & -5.23 \\
\hline Tnfrsf18 & NM_009400 & Tumor necrosis factor receptor superfamily, member 18 & -2.00 & -2.05 & -2.07 & -1.59 \\
\hline \multicolumn{7}{|c|}{ Response to stress antiapoptosis visual perception } \\
\hline Crygs & NM_009967 & Crystallin, $\gamma S$ & -2.29 & -2.30 & $-3.5 E+16$ & $-4.4 \mathrm{E}+15$ \\
\hline Crygd & NM_007776 & Crystallin, $\gamma D$ & -2.64 & -2.33 & $-7.4 \mathrm{E}+16$ & $-5.7 E+15$ \\
\hline Crygc & NM_001082573 & Crystallin, $\gamma \mathrm{C}$ & -2.70 & -2.78 & $-7.2 \mathrm{E}+15$ & $-6.2 \mathrm{E}+15$ \\
\hline Crybal & NM_009965 & Crystallin, $\beta A 1$ & -4.46 & -4.71 & $-7.5 E+15$ & $-4.4 \mathrm{E}+15$ \\
\hline Crybb1 & NM_023695 & Crystallin, $\beta B 1$ & -4.95 & -4.18 & -11.34 & -15.34 \\
\hline Cryaa & NM_013501 & Crystallin, $\alpha \mathrm{A}$ & -14.55 & -14.54 & $-4.4 \mathrm{E}+15$ & $-4.4 \mathrm{E}+15$ \\
\hline \multicolumn{7}{|c|}{ Regulation of transcription } \\
\hline Esrrb & NM_001159500 & Estrogen-related receptor $\beta$ & 2.85 & 3.44 & 2.30 & 2.82 \\
\hline En2 & NM_010134 & Engrailed homeobox 2 & 1.85 & 2.11 & 1.82 & 2.89 \\
\hline KIf15 & NM_023184 & Kruppel-like factor 15 & 1.51 & 2.01 & 1.90 & 2.03 \\
\hline \multicolumn{7}{|l|}{ Cell adhesion } \\
\hline Col6a1 & NM_009933 & Collagen, type VI, $\alpha 1$ & -1.88 & -2.06 & -2.79 & -2.73 \\
\hline Cldn5 & NM_013805 & Claudin 5 & -1.90 & -2.38 & -1.55 & -2.64 \\
\hline \multicolumn{7}{|c|}{ Metabolic process } \\
\hline Hs6st2 & NM_001077202 & Heparan sulfate 6-0-sulfotransferase 2 & 2.87 & 4.95 & 2.40 & 3.44 \\
\hline Pnpla3 & NM_054088 & Patatin-like phospholipase domain containing 3 & -2.05 & -2.31 & -2.51 & -2.67 \\
\hline \multicolumn{7}{|c|}{ Regulation of cell growth } \\
\hline Fam 107a & NM_183187 & Family with sequence similarity 107 , member A & 2.36 & 2.64 & 3.77 & 3.79 \\
\hline \multicolumn{7}{|c|}{ 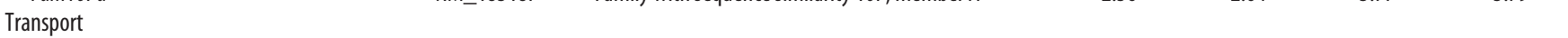 } \\
\hline$T c 2 n$ & NM_001082976 & Tandem C2 domains, nuclear & 2.74 & 2.65 & 8.35 & 8.38 \\
\hline $\operatorname{Scn} 7 a$ & NM_009135 & Sodium channel, voltage-gated, type VII, $\alpha$ & 2.12 & 2.83 & 1.85 & 2.30 \\
\hline \multicolumn{7}{|c|}{ veriom } \\
\hline Fam159b & NM_029984 & Family with sequence similarity 159 , member B & 2.10 & 3.10 & 2.43 & 5.30 \\
\hline Samd7 & NM_029489 & Sterile $\alpha$ motif domain containing 7 & 2.09 & 1.69 & 2.02 & 1.81 \\
\hline Agxt2/1 & NM_027907 & Alanine-glyoxylate aminotransferase 2-like 1 & 2.06 & 2.73 & 1.61 & 2.44 \\
\hline Acrbp & NM_016845 & Acrosin binding protein & -2.35 & -2.28 & -2.11 & -1.97 \\
\hline
\end{tabular}

Microarray analysis identified 88 genes with FC2 differentially expressed between 2 and 4 months compared with 1 month. Among them, 39 were present in RNAseq data analysis. These genes are potentially involved in the transient cell death occurring in $\mathrm{Nrl}^{-1-}$ retina between 1 and 4 months of age.

RPE plays a critical role in the maintenance of photoreceptor integrity (Strauss, 2005; Sparrow et al., 2010). The use of $R$ pe65 ${ }^{-1-} ; \mathrm{Nrl}^{-1-}$ mice has demonstrated the importance of RPE65 in both rods and cones (Wenzel et al., 2007; Feathers et al., 2008; Kunchithapautham et al., 2009). Surprisingly, we observed early RPE defects, including the loss of RPE65 expression in patches, RPE atrophy, and loss of tight junctions between 1 and 4 months in $\mathrm{Nrl}^{-1-}$ retina. We did not observe RPE65 in the whirls and rosettes as reported in one (Feathers et al., 2008) but not the other study (Wenzel et al., 2007). Thus, an absence of rod photoreceptors or secretion of a toxic product by excess cones appears to compromise the integrity of RPE. However, the remaining RPE65-positive RPE cells can renew the pool of 11-cis-retinal and maintain some light sensitivity at high-intensity stimulation. These observations can also be explained by the existence of a distinct visual pigment recycling pathway revealed in cone-rich retina of chicken and ground squirrels (Mata et al., 2002; Trevino et al., 2005). Indeed, Müller cells may contribute to maintenance of cone function in $\mathrm{Nrl}^{-1-}$ retina and compensate for RPE defect. We also noticed that the absence of RPE did not lead to lack of PNA staining, suggesting that cones secrete their own extracellular matrix (Mieziewska et al., 1993). The early RPE defect in $\mathrm{Nrl}^{-1-}$ retina might also indicate the existence of a rod-derived RPE survival factor.

In mouse models with no or short rod OSs, such as $\mathrm{Crx}^{-1-}$ (Furukawa et al., 1999) or Rho ${ }^{-1-}$ mice (Humphries et al., 1997), rod photoreceptors die within weeks. In fact, all rods are lost in most mouse retinal degeneration mutants, independent of cell death kinetics (Punzo et al., 2009; Bramall et al., 2010). In $\mathrm{Nrl}^{-1-}$ 
mice, however, although distinct cone OS are not detected by 4 months, many cones survive for an extended period of time. We suggest that cone death in $\mathrm{Nrl}^{-1-}$ mice is not intrinsic to photoreceptors but reflects an adaptive homeostatic mechanism. Rapid cell death allows the cone-only $\mathrm{Nrl}^{-1-}$ retina to accommodate the steep requirement of oxygen (Perkins et al., 2003; Daniele et al., 2005; Shen et al., 2005) by surviving cones.

Prolonged survival of many cones (two to four layers of nuclei even at 18 months) in $\mathrm{Nrl}^{-1-}$ retina, in the absence of rods since birth, demonstrates that rod photoreceptors are not essential for cone survival and may not be the sole source of trophic factors. For instance, $R d c v f$, first identified as a rod-derived cone viability factor able to preserve cone function (Léveillard et al., 2004; Yang et al., 2009), is also expressed in the INL (Lambard et al., 2010; Reichman et al., 2010). In $\mathrm{Nrl}^{-1-}$ retina, $R d c v f 1$ expression does not change with age although $R d c v f 2$ shows decreased expression between 1 and 10 months (data not shown). Even if the numbers of nuclei are preserved at older ages, we observed a slight second decline after 8 months in the ERG b-wave that may be attributed to cone aging, consistent with a small age-associated decline in rod and cone function in 12-month-old C57BL/6 mouse retina (Gresh et al., 2003; Parapuram et al., 2010).

The higher concentration of acrolein and MDA in 4-monthold $\mathrm{Nrl}^{-1-}$ retina corroborates the hypothesis that the average circulating current and oxygen demand in $\mathrm{Nrl}^{-1-}$ retina should be less compared with WT due to the difference in a-wave amplitude generated by rod and cone photoreceptors (Daniele et al., 2005). Thus, oxygen stress in $\mathrm{Nrl}^{-1-}$ mice should be higher, and hyperoxia may be toxic for photoreceptors. Interestingly, we observed attenuated retinal vasculature in older $\mathrm{Nrl}^{-1-}$ retina, leading to a decrease in oxygen supply that could be beneficial for cones. This provides further support for the hypothesis that $\mathrm{Nrl}^{-1-}$ retina are able to adapt and maintain a certain number of cones for prolonged period. The use of antioxidants in $\mathrm{Nrl}^{-1-}$ mice might also reduce photoreceptor cell death, as described in several models of retinitis pigmentosa (Cao and Phillis, 1995; Kowluru and Odenbach, 2004; Komeima et al., 2006).

Retinal detachment, oxidative stress due to retinal hyperoxia (Stone et al., 1999), and activation of microglia cells (Gupta et al., 2003; Glybina et al., 2009) have been associated with RP and are observed in $\mathrm{Nrl}^{-1-}$ retina. We suggest that these changes indicate a central role for rods in retinal homeostasis and not a direct impact on cone survival. As rods constitute almost $70 \%$ of cells in mouse and human retina, the loss of rods is expected to have a major influence on retinal architecture. Loss of rods compromises the fragile homeostasis in the retina of $\mathrm{Nrl}^{-/-}$mice, leading to RPE atrophy, Müller cell activation, altered retinal vasculature, and loss or dysfunction of other neuronal cell types. While additional investigations are necessary to delineate the underlying molecular pathways of cone survival, we suggest that functionally relevant contacts with RPE and trophic factors from Müller glia and microglia cells contribute in prolonged survival of cone photoreceptors even in the absence of rods. As $\mathrm{Nrl}^{-1-}$ mouse exhibits many features of retinal remodeling in other retinal degenerations, our studies may provide new insights into pathogenic mechanisms of retinal neurodegenerative diseases and allow evaluation of alternative therapies.

\section{References}

Akhmedov NB, Piriev NI, Chang B, Rapoport AL, Hawes NL, Nishina PM, Nusinowitz S, Heckenlively JR, Roderick TH, Kozak CA, Danciger M, Davisson MT, Farber DB (2000) A deletion in a photoreceptor-specific nuclear receptor mRNA causes retinal degeneration in the $\mathrm{rd} 7$ mouse. Proc Natl Acad Sci U S A 97:5551-5556.
Akimoto M, Cheng H, Zhu D, Brzezinski JA, Khanna R, Filippova E, Oh EC, Jing Y, Linares JL, Brooks M, Zareparsi S, Mears AJ, Hero A, Glaser T, Swaroop A (2006) Targeting of GFP to newborn rods by Nrl promoter and temporal expression profiling of flow-sorted photoreceptors. Proc Natl Acad Sci U S A 103:3890-3895.

Bernardos RL, Barthel LK, Meyers JR, Raymond PA (2007) Late-stage neuronal progenitors in the retina are radial Müller glia that function as retinal stem cells. J Neurosci 27:7028-7040.

Bobu C, Craft CM, Masson-Pevet M, Hicks D (2006) Photoreceptor organization and rhythmic phagocytosis in the nile rat Arvicanthis ansorgei: a novel diurnal rodent model for the study of cone pathophysiology. Invest Ophthalmol Vis Sci 47:3109-3118.

Bramall AN, Wright AF, Jacobson SG, McInnes RR (2010) The genomic, biochemical, and cellular responses of the retina in inherited photoreceptor degenerations and prospects for the treatment of these disorders. Annu Rev Neurosci 33:441-472.

Cao X, Phillis JW (1995) The free radical scavenger, alpha-lipoic acid, protects against cerebral ischemia-reperfusion injury in gerbils. Free Radic Res 23:365-370.

Chen J, Nathans J (2007) Genetic ablation of cone photoreceptors eliminates retinal folds in the retinal degeneration 7 (rd7) mouse. Invest Ophthalmol Vis Sci 48:2799-2805.

Cideciyan AV, Aleman TS, Jacobson SG, Khanna H, Sumaroka A, Aguirre GK, Schwartz SB, Windsor EA, He S, Chang B, Stone EM, Swaroop A (2007) Centrosomal-ciliary gene CEP290/NPHP6 mutations result in blindness with unexpected sparing of photoreceptors and visual brain: implications for therapy of Leber congenital amaurosis. Hum Mutat 28:1074-1083.

Curcio CA, Sloan KR, Kalina RE, Hendrickson AE (1990) Human photoreceptor topography. J Comp Neurol 292:497-523.

Daniele LL, Lillo C, Lyubarsky AL, Nikonov SS, Philp N, Mears AJ, Swaroop A, Williams DS, Pugh EN Jr (2005) Cone-like morphological, molecular, and electrophysiological features of the photoreceptors of the $\mathrm{Nrl}$ knockout mouse. Invest Ophthalmol Vis Sci 46:2156-2167.

Faktorovich EG, Steinberg RH, Yasumura D, Matthes MT, LaVail MM (1990) Photoreceptor degeneration in inherited retinal dystrophy delayed by basic fibroblast growth factor. Nature 347:83-86.

Feathers KL, Lyubarsky AL, Khan NW, Teofilo K, Swaroop A, Williams DS, Pugh EN Jr, Thompson DA (2008) Nrl-knockout mice deficient in Rpe65 fail to synthesize 11-cis retinal and cone outer segments. Invest Ophthalmol Vis Sci 49:1126-1135.

Fischer AJ, Reh TA (2003) Potential of Müller glia to become neurogenic retinal progenitor cells. Glia 43:70-76.

Fisher SK, Lewis GP (2003) Müller cell and neuronal remodeling in retinal detachment and reattachment and their potential consequences for visual recovery: a review and reconsideration of recent data. Vision Res 43:887-897.

Fort PE, Lampi KJ (2011) New focus on alpha-crystallins in retinal neurodegenerative diseases. Exp Eye Res 92:98-103.

Fort PE, Freeman WM, Losiewicz MK, Singh RS, Gardner TW (2009) The retinal proteome in experimental diabetic retinopathy: up-regulation of crystallins and reversal by systemic and periocular insulin. Mol Cell Proteomics 8:767-779.

Furukawa T, Morrow EM, Li T, Davis FC, Cepko CL (1999) Retinopathy and attenuated circadian entrainment in Crx-deficient mice. Nat Genet 23:466-470.

Gariano RF, Sage EH, Kaplan HJ, Hendrickson AE (1996) Development of astrocytes and their relation to blood vessels in fetal monkey retina. Invest Ophthalmol Vis Sci 37:2367-2375.

Glybina IV, Kennedy A, Ashton P, Abrams GW, Iezzi R (2009) Photoreceptor neuroprotection in RCS rats via low-dose intravitreal sustained-delivery of fluocinolone acetonide. Invest Ophthalmol Vis Sci 50:4847-4857.

Gresh J, Goletz PW, Crouch RK, Rohrer B (2003) Structure-function analysis of rods and cones in juvenile, adult, and aged C57BL/6 and BALB/c mice. Vis Neurosci 20:211-220.

Guérin CJ, Anderson DH, Fariss RN, Fisher SK (1989) Retinal reattachment of the primate macula. Photoreceptor recovery after short-term detachment. Invest Ophthalmol Vis Sci 30:1708-1725.

Gupta N, Brown KE, Milam AH (2003) Activated microglia in human retinitis pigmentosa, late-onset retinal degeneration, and age-related macular degeneration. Exp Eye Res 76:463-471. 
Hanisch UK, Kettenmann H (2007) Microglia: active sensor and versatile effector cells in the normal and pathologic brain. Nat Neurosci 10:1387-1394.

Hendrickson A, Hicks D (2002) Distribution and density of medium- and short-wavelength selective cones in the domestic pig retina. Exp Eye Res 74:435-444.

Humayun MS, Prince M, de Juan E Jr, Barron Y, Moskowitz M, Klock IB, Milam AH (1999) Morphometric analysis of the extramacular retina from postmortem eyes with retinitis pigmentosa. Invest Ophthalmol Vis Sci 40:143-148.

Humphries MM, Rancourt D, Farrar GJ, Kenna P, Hazel M, Bush RA, Sieving PA, Sheils DM, McNally N, Creighton P, Erven A, Boros A, Gulya K, Capecchi MR, Humphries P (1997) Retinopathy induced in mice by targeted disruption of the rhodopsin gene. Nat Genet 15:216-219.

Jackson GR, Owsley C, Curcio CA (2002) Photoreceptor degeneration and dysfunction in aging and age-related maculopathy. Ageing Res Rev 1:381-396.

Jacobson SG, Roman AJ, Aleman TS, Sumaroka A, Herrera W, Windsor EA, Atkinson LA, Schwartz SB, Steinberg JD, Cideciyan AV (2010) Normal central retinal function and structure preserved in retinitis pigmentosa. Invest Ophthalmol Vis Sci 51:1079-1085.

John SK, Smith JE, Aguirre GD, Milam AH (2000) Loss of cone molecular markers in rhodopsin-mutant human retinas with retinitis pigmentosa. Mol Vis 6:204-215.

Jones BW, Marc RE (2005) Retinal remodeling during retinal degeneration. Exp Eye Res 81:123-137.

Karl MO, Hayes S, Nelson BR, Tan K, Buckingham B, Reh TA (2008) Stimulation of neural regeneration in the mouse retina. Proc Natl Acad Sci U S A 105:19508-19513.

Komeima K, Rogers BS, Lu L, Campochiaro PA (2006) Antioxidants reduce cone cell death in a model of retinitis pigmentosa. Proc Natl Acad Sci U S A 103:11300-11305.

Kowluru RA, Odenbach S (2004) Effect of long-term administration of alpha-lipoic acid on retinal capillary cell death and the development of retinopathy in diabetic rats. Diabetes 53:3233-3238.

Kryger Z, Galli-Resta L, Jacobs GH, Reese BE (1998) The topography of rod and cone photoreceptors in the retina of the ground squirrel. Vis Neurosci 15:685-691.

Kumar PA, Haseeb A, Suryanarayana P, Ehtesham NZ, Reddy GB (2005) Elevated expression of alphaA- and alphaB-crystallins in streptozotocininduced diabetic rat. Arch Biochem Biophys 444:77-83.

Kunchithapautham K, Coughlin B, Crouch RK, Rohrer B (2009) Cone outer segment morphology and cone function in the Rpe65 ${ }^{-1-} \mathrm{Nrl}^{-1-}$ mouse retina are amenable to retinoid replacement. Invest Ophthalmol Vis Sci 50:4858-4864.

Lambard S, Reichman S, Berlinicke C, Niepon ML, Goureau O, Sahel JA, Léveillard T, Zack DJ (2010) Expression of rod-derived cone viability factor: dual role of CRX in regulating promoter activity and cell-type specificity. PLoS One 5:e13075.

Langmann T (2007) Microglia activation in retinal degeneration. J Leukoc Biol 81:1345-1351.

Léveillard T, Mohand-Saïd S, Lorentz O, Hicks D, Fintz AC, Clérin E, Simonutti M, Forster V, Cavusoglu N, Chalmel F, Dollé P, Poch O, Lambrou G, Sahel JA (2004) Identification and characterization of rod-derived cone viability factor. Nat Genet 36:755-759.

Lewis GP, Linberg KA, Fisher SK (1998) Neurite outgrowth from bipolar and horizontal cells after experimental retinal detachment. Invest Ophthalmol Vis Sci 39:424-434.

Lewis GP, Chapin EA, Luna G, Linberg KA, Fisher SK (2010) The fate of Müller's glia following experimental retinal detachment: nuclear migration, cell division, and subretinal glial scar formation. Mol Vis 16:1361-1372.

Lu F, Zhao P, Fan Y, Tang S, Hu J, Liu X, Yang X, Chen Y, Li T, Lei C, Yang J, Lin Y, Ma S, Li C, Shi Y, Yang Z (2010) An association study of SERPING1 gene and age-related macular degeneration in a Han Chinese population. Mol Vis $16: 1-6$.

Luo DG, Xue T, Yau KW (2008) How vision begins: an odyssey. Proc Natl Acad Sci U S A 105:9855-9862.

Marc RE, Jones BW, Watt CB, Strettoi E (2003) Neural remodeling in retinal degeneration. Prog Retin Eye Res 22:607-655.

Marioni JC, Mason CE, Mane SM, Stephens M, Gilad Y (2008) RNA-seq: an assessment of technical reproducibility and comparison with gene expression arrays. Genome Res 18:1509-1517.

Mata NL, Radu RA, Clemmons RC, Travis GH (2002) Isomerization and oxidation of vitamin A in cone-dominant retinas: a novel pathway for visual-pigment regeneration in daylight. Neuron 36:69-80.

Mears AJ, Kondo M, Swain PK, Takada Y, Bush RA, Saunders TL, Sieving PA, Swaroop A (2001) $\mathrm{Nrl}$ is required for rod photoreceptor development. Nat Genet 29:447-452.

Mieziewska K, Van Veen T, Aguirre GD (1993) Development and fate of interphotoreceptor matrix components during dysplastic photoreceptor differentiation: a lectin cytochemical study of rod-cone dysplasia 1. Exp Eye Res 56:429-441.

Milam AH, Li ZY, Fariss RN (1998) Histopathology of the human retina in retinitis pigmentosa. Prog Retin Eye Res 17:175-205.

Mullins RF, Faidley EA, Daggett HT, Jomary C, Lotery AJ, Stone EM (2009) Localization of complement 1 inhibitor (C1INH/SERPING1) in human eyes with age-related macular degeneration. Exp Eye Res 89:767-773.

Mustafi D, Engel AH, Palczewski K (2009) Structure of cone photoreceptors. Prog Retin Eye Res 28:289-302.

Mustafi D, Kevany BM, Genoud C, Okano K, Cideciyan AV, Sumaroka A, Roman AJ, Jacobson SG, Engel A, Adams MD, Palczewski K (2011) Defective photoreceptor phagocytosis in a mouse model of enhanced S-cone syndrome causes progressive retinal degeneration. FASEB J 25:3157-3176.

Nikonov SS, Daniele LL, Zhu X, Craft CM, Swaroop A, Pugh EN Jr (2005) Photoreceptors of $\mathrm{Nrl}^{-1-}$ mice coexpress functional S- and M-cone opsins having distinct inactivation mechanisms. J Gen Physiol 125:287-304.

Oh EC, Khan N, Novelli E, Khanna H, Strettoi E, Swaroop A (2007) Transformation of cone precursors to functional rod photoreceptors by bZIP transcription factor NRL. Proc Natl Acad Sci U S A 104:1679-1684.

Oh EC, Cheng H, Hao H, Jia L, Khan NW, Swaroop A (2008) Rod differentiation factor NRL activates the expression of nuclear receptor NR2E3 to suppress the development of cone photoreceptors. Brain Res 1236:16-29.

Pang JJ, Chang B, Hawes NL, Hurd RE, Davisson MT, Li J, Noorwez SM, Malhotra R, McDowell JH, Kaushal S, Hauswirth WW, Nusinowitz S, Thompson DA, Heckenlively JR (2005) Retinal degeneration 12 (rd12): a new, spontaneously arising mouse model for human Leber congenital amaurosis (LCA). Mol Vis 11:152-162.

Paques M, Guyomard JL, Simonutti M, Roux MJ, Picaud S, Legargasson JF, Sahel JA (2007) Panretinal, high-resolution color photography of the mouse fundus. Invest Ophthalmol Vis Sci 48:2769-2774.

Parapuram SK, Cojocaru RI, Chang JR, Khanna R, Brooks M, Othman M, Zareparsi S, Khan NW, Gotoh N, Cogliati T, Swaroop A (2010) Distinct signature of altered homeostasis in aging rod photoreceptors: implications for retinal diseases. PLoS One 5:e13885.

Peng YW, Hao Y, Petters RM, Wong F (2000) Ectopic synaptogenesis in the mammalian retina caused by rod photoreceptor-specific mutations. Nat Neurosci 3:1121-1127.

Perkins GA, Ellisman MH, Fox DA (2003) Three-dimensional analysis of mouse rod and cone mitochondrial cristae architecture: bioenergetic and functional implications. Mol Vis 9:60-73.

Punzo C, Kornacker K, Cepko CL (2009) Stimulation of the insulin/mTOR pathway delays cone death in a mouse model of retinitis pigmentosa. Nat Neurosci 12:44-52.

Rao NA, Saraswathy S, Wu GS, Katselis GS, Wawrousek EF, Bhat S (2008) Elevated retina-specific expression of the small heat shock protein, alphaA-crystallin, is associated with photoreceptor protection in experimental uveitis. Invest Ophthalmol Vis Sci 49:1161-1171.

Raven MA, Oh EC, Swaroop A, Reese BE (2007) Afferent control of horizontal cell morphology revealed by genetic respecification of rods and cones. J Neurosci 27:3540-3547.

Reichman S, Kalathur RK, Lambard S, Ait-Ali N, Yang Y, Lardenois A, Ripp R, Poch O, Zack DJ, Sahel JA, Léveillard T (2010) The homeobox gene CHX10/VSX2 regulates RdCVF promoter activity in the inner retina. Hum Mol Genet 19:250-261.

Rex TS, Lewis GP, Geller SF, Fisher SK (2002) Differential expression of cone opsin mRNA levels following experimental retinal detachment and reattachment. Mol Vis 8:114-118.

Roger J, Brajeul V, Thomasseau S, Hienola A, Sahel JA, Guillonneau X, Goureau O (2006) Involvement of pleiotrophin in CNTF-mediated 
differentiation of the late retinal progenitor cells. Dev Biol 298: $527-539$.

Santos A, Humayun MS, de Juan E Jr, Greenburg RJ, Marsh MJ, Klock IB, Milam AH (1997) Preservation of the inner retina in retinitis pigmentosa. A morphometric analysis. Arch Ophthalmol 115:511-515.

Shen J, Yang X, Dong A, Petters RM, Peng YW, Wong F, Campochiaro PA (2005) Oxidative damage is a potential cause of cone cell death in retinitis pigmentosa. J Cell Physiol 203:457-464.

Sparrow JR, Hicks D, Hamel CP (2010) The retinal pigment epithelium in health and disease. Curr Mol Med 10:802-823.

Stone J, Maslim J, Valter-Kocsi K, Mervin K, Bowers F, Chu Y, Barnett N, Provis J, Lewis G, Fisher SK, Bisti S, Gargini C, Cervetto L, Merin S, Peér J (1999) Mechanisms of photoreceptor death and survival in mammalian retina. Prog Retin Eye Res 18:689-735.

Stone JL, Barlow WE, Humayun MS, de Juan E Jr, Milam AH (1992) Morphometric analysis of macular photoreceptors and ganglion cells in retinas with retinitis pigmentosa. Arch Ophthalmol 110:1634-1639.

Strauss O (2005) The retinal pigment epithelium in visual function. Physiol Rev 85:845-881.

Strettoi E, Mears AJ, Swaroop A (2004) Recruitment of the rod pathway by cones in the absence of rods. J Neurosci 24:7576-7582.

Swaroop A, Kim D, Forrest D (2010) Transcriptional regulation of photoreceptor development and homeostasis in the mammalian retina. Nat Rev Neurosci 11:563-576.

Trevino SG, Villazana-Espinoza ET, Muniz A, Tsin AT (2005) Retinoid cycles in the cone-dominated chicken retina. J Exp Biol 208:4151-4157.

Umeda S, Suzuki MT, Okamoto H, Ono F, Mizota A, Terao K, Yoshikawa Y,
Tanaka Y, Iwata T (2005) Molecular composition of drusen and possible involvement of anti-retinal autoimmunity in two different forms of macular degeneration in cynomolgus monkey (Macaca fascicularis). FASEB J 19:1683-1685.

Wenzel A, von Lintig J, Oberhauser V, Tanimoto N, Grimm C, Seeliger MW (2007) RPE65 is essential for the function of cone photoreceptors in NRL-deficient mice. Invest Ophthalmol Vis Sci 48:534-542.

West H, Richardson WD, Fruttiger M (2005) Stabilization of the retinal vascular network by reciprocal feedback between blood vessels and astrocytes. Development 132:1855-1862.

Wright AF, Chakarova CF, Abd El-Aziz MM, Bhattacharya SS (2010) Photoreceptor degeneration: genetic and mechanistic dissection of a complex trait. Nat Rev Genet 11:273-284.

Yang Y, Mohand-Said S, Danan A, Simonutti M, Fontaine V, Clerin E, Picaud S, Léveillard T, Sahel JA (2009) Functional cone rescue by RdCVF protein in a dominant model of retinitis pigmentosa. Mol Ther 17:787-795.

Yoshida S, Mears AJ, Friedman JS, Carter T, He S, Oh E, Jing Y, Farjo R, Fleury G, Barlow C, Hero AO, Swaroop A (2004) Expression profiling of the developing and mature $\mathrm{Nrl}^{-/-}$mouse retina: identification of retinal disease candidates and transcriptional regulatory targets of Nrl. Hum Mol Genet 13:1487-1503.

Zhu X, Brown B, Li A, Mears AJ, Swaroop A, Craft CM (2003) GRK1dependent phosphorylation of $\mathrm{S}$ and $\mathrm{M}$ opsins and their binding to cone arrestin during cone phototransduction in the mouse retina. J Neurosci 23:6152-6160. 